\title{
Design of Balanced Energy Savings Performance Contracts
}

\author{
Barış Tan \\ College of Administrative Sciences and Economics and College of Engineering \\ Koç University, Rumeli Feneri Yolu, Sariyer, 34450, Istanbul, Turkey
}

\author{
ARTICLE HISTORY \\ Compiled December 12, 2019
}

\begin{abstract}
Energy savings performance contracts between the energy users and the energy service companies (ESCO) are used to finance energy efficiency investments by using the future energy savings that will result from these investments. We present an analytical model to characterize the energy savings performance contracts and discuss how the risks of estimating the energy savings affect the energy user and the service provider. This characterization allows determination of the contract parameters for a balanced contract with the information about the energy savings that are expected from the planned energy efficiency investments. Since it is difficult to get the statistical information about the energy savings before investing in an energy efficiency project, we develop a distribution-free contract that sets the guaranteed energy savings level based on the mean and the standard deviation of the energy savings and the profit-sharing ratio between the ESCO and the energy user. We show that a simple distribution-free balanced contract performs satisfactorily when the distribution of the energy savings is not known and its mean and the standard deviation are estimated with error. Our analytical results show that the energy savings contracts with the right parameters can mitigate the risks related to realization of the anticipated energy savings.
\end{abstract}

\section{KEYWORDS}

Energy Efficient Manufacturing, Contracting, Stochastic Models, Newsvendor

\section{Introduction}

The total energy consumption in the world is expected to increase by $40 \%$ until 2040 . Despite the developments in the alternative energy sources, fossil fuels will still account for more than $75 \%$ of energy use and carbon dioxide emissions are expected to increase despite the international efforts until 2040 (EIA 2017).

Improving energy efficiency is an effective way of responding to the increasing energy demand in the world in a sustainable way (IEA 2019). The objective of this study is to develop an analytical framework to model, analyze, and design energy savings performance contracts to help investments in energy efficiency projects.

The main motivation for this study stemmed from the need to increase energy efficiency in buildings and in manufacturing. The residential and commercial buildings accounted for $21 \%$ and the industrial sector that includes mining, manufacturing, agriculture, and construction accounted for $55 \%$ of the world delivered energy consumption

Tan, B. (2019), "Design of Balanced Energy Savings Performance Contracts", International Journal of Production Research, DOI: 10.1080/00207543.2019.1641240 
in 2015 (EIA 2017). 36\% of global final energy use and close to $40 \%$ of energy-related carbon dioxide emissions are generated by buildings construction and operations in 2017 (IEA 2018).

While new energy-efficient buildings can be built, the existing buildings will still continue to account for the major part of energy consumption. Similarly, while new energy-efficient manufacturing plants can be built, $40 \%$ of the energy used at the existing manufacturing plants directly or indirectly is lost (Brueske et al. 2012; Edgar and Pistikopoulos 2018). In such an environment, improving energy efficiency at the existing buildings and manufacturing plants is of utter importance (IEA 2019).

Although energy efficiency can be improved significantly by investing in various energy efficiency measures, high investment costs for installing and/or replacing materials and equipment with more efficient ones and long payback periods can be seen as obstacles for energy efficiency investments (Aflaki et al. 2013; Muthulingam et al. 2013; Blass et al. 2014; Trianni et al. 2016; Bertoldi and Boza-Kiss 2017). However, investing in energy efficiency measures can decrease energy consumption and therefore carbon dioxide emissions and at the same time decrease energy costs. Savings in energy costs can finance the initial investments and also bring additional financial benefits above the initial investment. Developing alternative ways of financing energy efficiency investments is expected to increase the number of the energy-efficiency projects implemented by the energy users (Rezessy and Bertoldi 2010).

In order to address the need for increasing energy efficiency implementations, energy service companies (ESCO) provide a wide range of energy related services such as power generation, energy supply, energy infrastructures, conservation, design and implementation of energy saving projects among others. The energy service company term is used for companies that develop, install and finance comprehensive, performance-based projects with a 5 to 10-year duration to improve the energy efficiency of facilities owned or operated by a customer (Vine 2005). ESCOs use a business model that offers energy-saving projects as a service (Bertoldi and Boza-Kiss 2017; Stuart et al. 2018). In the energy-saving business models, a firm offers making all or a part of the necessary energy efficiency investments for a client in exchange of a service fee and a fraction of the energy cost savings for a predetermined time period. The firm can also offer certain guarantees and targets related to the energy savings that will be achieved as a result of these investments to the clients.

Energy service performance contracting is a type of contracting between an ESCO and an energy user where the ESCO identifies the possible energy efficiency measures for the energy user, guarantees a part of the infrastructure investment payments, helps its customers about implementation and gives required consultancy to improve energy efficiency (Selviaridis and Wynstra 2015).

Energy performance contracting is usually grouped into two categories according to the contract types (Shang et al. 2017). The first category is the guaranteed savings contract where a predetermined level of savings for the contract period is guaranteed by the ESCO. This contract type enables the customers to take no risk for the energy savings performance contract and the ESCO carries the risk of obtaining a lower-thanexpected savings level. Since the ESCO guarantees a predetermined level of savings, obtaining a lower energy savings level might result in a profit loss for the ESCO. Customers who choose the guaranteed savings contracts are responsible for financing the capital on their own or through a financial loan. The financial organization that provides the loan work directly with the customers for assessing and managing the credit risk and can offer a lower financial cost to the customer.

The second category is the shared savings contracts where the ESCO makes the 
investment in exchange of getting a part of the energy savings. Since the ESCO is responsible for repaying the loan and taking the credit risk, the ESCO takes both the performance and credit risk while there is no risk for the energy user.

An energy savings performance contract between an ESCO and its client introduces different degree of risks for both parties (Lee et al. 2015). The payment for the ESCO is based on meeting the agreed performance criteria with the customer. If the parameters of the contract are set correctly by considering the risk implications for the parties involved, all the parties benefit from this service financially. The firm that offers the service and the energy user that receives the service can gain substantial financial returns with acceptable risk. The client pays a fraction of its energy bill with this agreement. Furthermore, realized energy savings will decrease carbon dioxide emissions and also ease the burden on future energy investments. As a result, this is a win-winwin arrangement for the firm, its client, and also for the environment.

In this study, we present an analytical model to characterize the energy savings performance contracts and discuss how the risks of overestimating and underestimating the energy savings affect the energy user and the service provider. This characterization allows determination of the contract parameters for a balanced contract with the information about the energy savings that are expected from the planned energy efficiency investments. Namely, we would like to answer the following questions: how should the parameters of a guaranteed savings contract be set based on the limited information about the anticipated energy savings? and how do the guaranteed and target savings levels and the shares of the savings above the target level and below the guaranteed level specified in the energy savings performance contract affect the profit risks for the energy user and for the ESCO?

Obtaining statistical information about energy savings from energy efficiency investments is a challenging task. Uncertainty of the energy usage, the energy prices, and the performance of the energy efficiency measures when they are applied to a particular building or a plant affects the energy savings from energy efficiency investments. This uncertainty and the difficulty of estimating energy savings also affect adoption of the energy performance contracts (Lee et al. 2013).

In order to address the difficulty of estimating the statistical distribution of the energy savings that will be obtained from an energy efficiency project, we develop a distribution-free contract that sets the guaranteed savings level based on the estimated mean, the standard deviation, and the profit-sharing ratio between the ESCO and the energy user. We further simplify this contract for the case where no additional information is available on setting the downside risk probabilities for the ESCO and the energy user. For the case where the same probability of obtaining a profit above a given threshold is used as a risk measure, we also present a simple distribution-free contract. This contract guarantees an energy savings level that is 0.35 standard deviation below the expected savings and allocates the realized energy savings above the guaranteed level equally between the energy user and the ESCO. Through numerical experiments, we show that this distribution-free simple contract performs satisfactorily for the energy user and for the ESCO.

The main contributions of this study are twofold. First, we develop an analytical model that allows characterization of the energy performance contracts and determination of the contract parameters based on a balanced contract. Second, based on our analytical characterization, we propose a distribution-free contract when the statistical information of the energy savings expected from an energy efficiency investment is limited. We show that this contract performs satisfactorily compared to an optimal contract that can be designed with full information. 
The analytical results given in this study can easily be put in practice and used. For example, the contacts analyzed for the practical cases in the buildings industry as described in (Coppens 2013; Lee et al. 2015) can be prepared by using the alternative approach presented in this study.

The organization of the remaining part of this study is as follows. In Section 2, we review the pertinent literature on analytical analysis of the energy performance contracts. We present the model and its assumptions in Section 3. The analysis of the model is given in Section 4. Section 5 presents a distribution-free contract that can be used when the expectation and the standard deviation of the energy saving are known but the distribution of the energy saving is not available. Numerical results are given for the performance of the distribution-free contracts in Section 6. Finally, conclusions are given in Section 7.

\section{Past Work}

There are many studies in the energy literature that focus on the qualitative discussion of energy performance contracts, e.g., (Goldman et al. 2005; Vine 2005).

In this review, we focus on the studies that analyze the Energy Performance Contracts by using quantitative computational models. Few papers focus on the decisionmaking process in a competitive environment and model the interaction among the energy user, ESCO, and the government by using game-theoretic models, e.g. (Shang et al. 2015; Zhou and Huang 2016; Shantia et al. 2018; Yi and Li 2018) among others. In these papers, a particular contract type is assumed and the interaction among different decision makers is analyzed by using the contract. These papers are not directly related to our study since we focus on the effect of the contract on the energy user and the ESCO in terms of their expected profits and risks in our model.

There are many different contract types used in the literature (Selviaridis and Wynstra 2015; Shang et al. 2017) . In this study, we use a general contract structure that covers most of the contract types in order understand the role of the contract parameters on the profits of the energy user and the ESCO. In order to analyze the effects of the contract parameters, we focus on evaluating the performance of a contract based on its parameters.

\subsection{Evaluating the Performance of a Given Contract}

For a given contract type, a number of studies focus on determining the outcome of the project in terms of the profit for the energy user and the ESCO depending on the model parameters in a deterministic setting. Yik and Lee (2004) use a deterministic model to evaluate the outcome of a guaranteed savings model. Tan et al. (2016) present a mathematical programming formulation to select the energy efficiency measures for existing buildings. They investigate the operation of a shared savings business model where an ESCO makes the initial investment and gets a fraction of the energy cost savings in a multi-period setting. Qin et al. (2017) present a model to select an energy performance contracting business model among the alternatives by using a multi-criteria decision-making model that captures the preferences of the decision makers related to a number of criteria. Carbonara and Pellegrino (2018)present a model to select the energy performance contracting structure for energy efficiency projects that are implemented through public-private partnerships by using a deterministic net present value model. Shang et al. (2015) analyze the benefit allocation in the shared-savings energy 
performance contracting projects by using a deterministic bargaining model between an energy user and an ESCO.Due to the uncertainty in energy cost savings and energy prices, these deterministic models cannot be used to evaluate the performance of an energy-savings contract in a random environment.

The stochastic models developed to analyze the energy-savings contracts are evaluated either computationally or by using simulation in the literature. Lee et al. (2015) analyze the energy performance contracts by using the zero-dollar collar option model by using a numerical approach. They use the binomial lattice model to determine the profit sharing between an energy user and an ESCO that use a guaranteed savings energy performance contract. Tan and Yavuz (2015) present a stochastic model to study the shared saving business model for a setting where the cost of technology decreases and the energy efficiency improves with time and the energy consumption, the energy price, the useful life of technology are uncertain. This study evaluates the expected value of the profit and discusses selection of the contract parameters that brings financial benefits to both parties by using an analytical approach.

Coppens (2013) presents a simulation model to analyze the shared profit and the guaranteed saving contracts and uses this model to analyze different case studies related to retrofitting existing buildings. Glumac et al. (2015) present a systems dynamics simulation model to analyze the interaction between different maintenance scenarios, external energy factors and case-specific conditions in the implementation of energy efficiency measures. Deng et al. (2014) present a stochastic model to determine the contact period and use simulation to evaluate the model. Deng et al. (2015) present a model that analyzes the guaranteed saving contracts to decide on the guaranteed saving level without losing profit in a competitive market. They analyze a multi-period stochastic model with uncertain energy price fluctuation and facility performance variability by using Monte Carlo simulation. Töppel and Tränkler (2019) compare the risk mitigation performance of different energy performance contracts based on a stochastic model that captures uncertainty in weather, commodity prices, and technological energy efficiency performance. They use simulation to make the comparison.

This study contributes to the literature on contract evaluation in two ways. First, we use a general contract representation that covers all the contract types considered in the literature as opposed to assuming a particular contract type. Second, this study gives an analytical characterization of the contracts as opposed to presenting numerical methods to analyze the contracts. This characterization allows us to analyze the profits and risks for the energy user and the ESCO for a general contract. This approach focuses on the inter-relationship among the contract parameters and shows how these parameters affect the risks of overestimating or underestimating the cost savings for the energy user and the ESCO. We use this characterization with the balanced contract approach used in the literature, e.g. (Lee et al. 2015; Deng et al. 2015), to construct a simple contract that uses the limited information about the energy savings.

\subsection{Evaluating the Trade-offs in Performance Contracts}

Modeling the trade-offs related to achieving energy savings that are above or below the guaranteed savings is similar to the Newsvendor Problem in the operations research literature. Different types of contracts used in a supply chain setting have been analyzed extensively by using game theory. The closest studies to the analysis of the energy savings performance contracts studied in this paper are the ones that analyze 
the shared savings contracts in a supply chain setting (Corbett and DeCroix 2001; Corbett et al. 2005). Corbett and DeCroix (2001) analyze equilibrium responses of a buyer and its supplier, consumption, and total profits, and show how these change with the contract parameters when a shared-revenue contract is used in a deterministic setting. Corbett et al. (2005) use a double-hazard framework to show that simple linear contracts are sufficient in many cases when the contract parameters are chosen carefully.

The main differences between the supply chain setting and the energy savings performance contracting are in the types of the contracts used, the relative power of the energy user compared to the ESCO, and the effect of the uncertainty on the contract. Consequently, the results presented for the supply chain contracting cannot be used directly for the energy savings performance contracts. In our setting, the energy user owns the energy efficiency project and can continue its operation without investing in an energy efficiency project. Furthermore, there are usually multiple ESCOs in the market. As a result, the energy user and the ESCO do not determine the contract parameters in a competitive equilibrium. The energy user negotiates with an ESCO that provides the most favorable agreement based on analysis of the energy savings opportunity. In addition, the energy savings that will be obtained from an energy efficiency project in a new building or in a new project is highly uncertain due to the uncertainty of the future energy prices, the usage, and the performance of the project. As a result, the main focus of the contracting problem for the energy savings performance contracts is on the determination of the contract parameters. This study contributes to the literature on evaluating the trade-offs in performance contracts by analyzing a new setting where the parameters of the performance contract are determined based on the balanced contract.

We consider the analytic characterization of the interaction among the parameters of a general energy savings performance contract that includes the guaranteed and the target levels, the penalty and the reward terms based on the realization of the performance, utilizing this characterization to derive results regarding the energy savings contracts and their parameters, and developing a distribution-free contract as the main contributions of this study.

\section{Model}

We consider a setting where an energy efficiency project that is expected to yield energy cost savings is identified. The energy cost savings that will be obtained from this project is uncertain at the time the contract is prepared. The estimates of the mean and standard deviation are available to the energy user and the ESCO. We consider two cases where the probability distribution of the saving is either available or not available. The cost of implementing this project is known with certainty at this stage. Then an energy savings performance contract that sets the guaranteed and target levels and includes the reward and penalty terms that are determined based on the realized energy savings is prepared. An ESCO that will implement the project according to the terms of the contract is selected for an upfront payment that is received as the fee. After the ESCO implemented the project, the actual savings are realized. Depending on the realization of the saving with respect to the guaranteed and target levels, the additional payments to the ESCO and the energy user are determined. Once these payments are made, the project is completed. The sequence of events is depicted in Figure 1. 


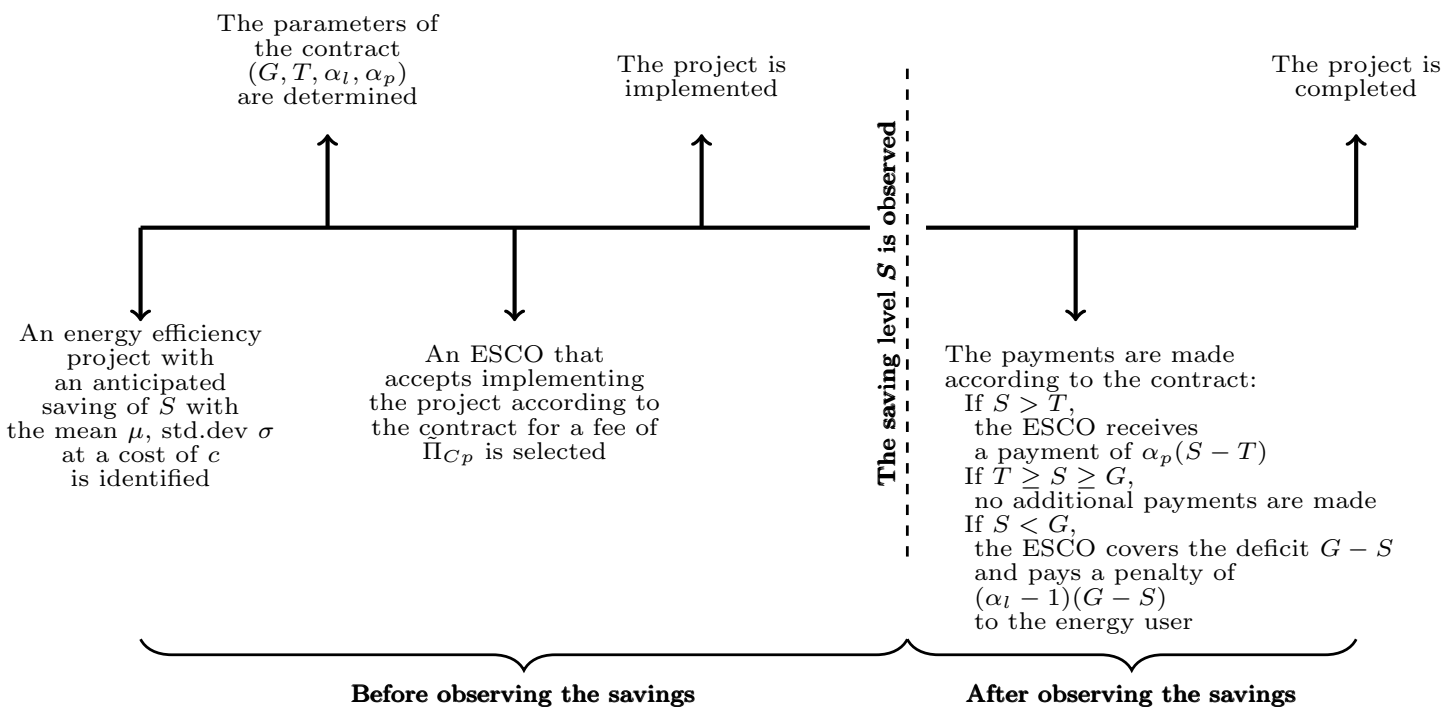

Figure 1. The sequence of the events

\subsection{Energy Efficiency Project}

The energy cost savings that will be obtained after implementing the energy efficiency project is denoted with $S$. Since each energy efficiency project is unique, the outcome of using an energy efficiency measure on a new building or plant is not known with certainty. Furthermore, the future energy prices and the energy usage are uncertain. As a result, $S$ is uncertain at the time of deciding on the contract. We represent the energy cost saving $S$ as a random variable with the probability distribution function $F(s)=\operatorname{prob}(S \leq s)$, the probability density function $f(s)$, the expectation $E[S]=\mu$ and the variance $E\left[(S-\mu)^{2}\right]=\sigma^{2}$. For a discussion of estimating the energy savings for energy performance contracting projects, the reader is referred to (Lee et al. 2013). In this study, we discuss how the contract parameters can be determined for two cases when $F(s)$ is known and when $\mu$ and $\sigma$ are known but $F(s)$ is not available.

The cost of the project at the time of preparing the contract is $c$. The project cost is known with certainty by the ESCO and the energy user.

The project profit that will be realized at the end of the project is $\Pi_{p}$ that is the difference between the realized energy saving and the cost of the project:

$$
\Pi_{p}=S-c .
$$

Since $S$ is random, the expected project profit is $E\left[\Pi_{p}\right]=\mu-c$. The expected project profit is shared between the ESCO and the energy user according to the energy savings performance contract.

\subsection{Energy Savings Performance Contract}

We consider a general description of an energy savings performance contract that includes the guaranteed and the target energy savings levels and also the reward and the penalty terms that are determined after the implementation of the project when the realized savings are observed. This general representation covers most of the different types of contracts used. 
We represent a general performance contract by four parameters $\left(G, T, \alpha_{l}, \alpha_{p}\right)$ where $G$ is the guaranteed energy cost saving, $T, T \geq G$, is the target energy cost saving, $\alpha_{l}$ is the ESCO's share to cover the energy cost deficit with respect to the guaranteed amount when the actual energy cost saving is lower than the guaranteed level, and $\alpha_{p}$ is the ESCO's share of the additional benefit that will be obtained when the actual cost saving is greater than the target energy cost saving. The term $\alpha_{p}$ is the per unit reward the ESCO receives for obtaining an energy savings level that exceeds the target level set in the contract. Similarly, the term $1-\alpha_{l}$ is the per unit penalty charges to the ESCO for obtaining an energy savings level that is below the guaranteed level in addition to covering the deficit between the guaranteed and the realized savings levels.

The ESCO is paid an upfront fee of $\tilde{\Pi}_{C p}$ to implement the energy efficiency project according to this contract.

After the energy savings are observed following the implementation of the energy efficiency project, the payments to the ESCO and the energy user are made according to the contract:

- if the realized saving is greater than the target level $S>T$, the ESCO receives a portion of the saving above the target level with a payment of $\alpha_{p}(S-T)$;

- if the realized saving is between the target level and the guaranteed level, $T \geq$ $S \geq G$, no additional payments are made;

- if the realized saving is below the guaranteed level $S<G$, the ESCO covers the deficit $G-S$ to make it sure that the energy user receives the guaranteed energy saving and pays a penalty of $\left(\alpha_{p}-1\right)(G-S)$ to the energy user.

For example, if the expected energy cost saving is $\$ 1,000,000$ and the cost of the project is $\$ 600,000$. The cost of the project can be financed by using the guaranteed level of the energy saving that will be secured through an energy performance contract. An agreement with an ESCO can guarantee an energy saving level of $G=\$ 800,000$ for a total fee of $\tilde{\Pi}_{C p}=\$ 100,000$. This arrangement guarantees a profit of $\$ 300,000$ for the energy user.

In the guaranteed savings contract, the energy user finances the investments for the energy saving technologies, usually recommended by the ESCO, by using a loan from a bank or by leasing the equipment. The ESCO guarantees the performance of the investment in energy saving technologies through a contract that includes a service fee during the project duration. If the guaranteed energy saving level, $G$ is not achieved, the ESCO covers the difference according to the contract (Lee et al. 2015).

In most of the guaranteed saving contracts used in the industry, the ESCO is responsible of covering the deficit, $G-S$ when the actual saving is below the guaranteed saving, $S<G$, e.g., (Lee et al. 2015). This case corresponds to using $\alpha_{l}=1$ in our model. In some other implementations in different countries, the ESCO is expected to pay a penalty in addition to covering the deficit, e.g. (Coppens 2013; Deng et al. 2015). In this case, $\alpha_{l}>1$ and the ESCO makes an additional payment of $\left(\alpha_{l}-1\right)(G-S)$ to the energy user and also covers the deficit. We assume $\alpha_{l} \geq 1$ for the general case. Since $\alpha_{p}$ is the ESCO's share of the realized cost saving above the guaranteed level, the energy user's share is $1-\alpha_{p}$ and $0 \leq \alpha_{p} \leq 1$.

Furthermore, in certain contracts, the target energy cost saving and the guaranteed cost saving are set to the same level, $T=G$, e.g., (Coppens 2013; Deng et al. 2015) while in some other implementation, the target level is set above the guaranteed level, $T>G$, e.g., (Lee et al. 2015). In the shared saving contracts, there is no guarantee and therefore $T=G=0$, e.g., (Tan and Yavuz 2015). The general contract defined above covers all these cases through selection of its parameters. 
For the shared saving contract where $G=T=0$, the energy user does not face any risk since all the risk is carried by the ESCO. In this case, the effect of the contract parameter $\alpha_{p}$ is straight forward: $\alpha_{p}$ should be set to cover the initial investments and also, the agreed additional profit to the ESCO. In the remaining part of this study, we focus on the guaranteed saving contracts where $T \geq G>0$.

\subsection{The Upfront Payment to the ESCO}

The upfront payment that will be paid to the ESCO as the fee, $\tilde{\Pi}_{C p}$ depends on many factors including the number of ESCOs with different risk behaviors, the availability of possible projects in the market, the negotiation power of the ESCO and the energy user. The negotiation between the energy user and the ESCO determines how the surplus between the guaranteed energy savings level and the cost of the project is shared.

An ESCO makes an effort to investigate and identify energy savings for each specific energy user with the expectation that the profit that will be received from a given project will be attractive. We analyze the problem where $\tilde{\Pi}_{C p}$ is exogenously given for the ESCO's services regarding the performance of the energy saving project and also, for guaranteeing a given level of performance. This fee is paid to the ESCO from the expected profit of the project. We consider the case where the energy user makes an agreement with an ESCO that offers the best preferable fee for the guaranteed energy savings level. We do not incorporate the fee negotiation in our model since this requires making specific assumptions about how the negotiation takes place depending on the characteristics of the ESCO, the energy user, and the market.

\subsection{Project Length}

We incorporate the effect of the project length through the definition of $S, G$, and $T$. Namely, the realized energy saving, the guaranteed and target energy saving levels correspond to the quantities for the whole project duration. This approach assumes that the payments of the reward and penalties are done at the end of the project duration. In certain contracts, the timing of the payments can be different. Although this feature can be added into the model, we use the assumption that all the payments take place at the end of the project to simplify the modeling and focus on the trade-offs between overestimating and underestimating the energy savings for the whole project duration.

\subsection{The Profits of the ESCO and the Energy User}

The project profit $\Pi_{p}$ is shared between the ESCO and the energy user. The profits of the ESCO and the energy user are denoted with $\Pi_{C p}$ and $\Pi_{U p}$ and $\Pi_{p}=\Pi_{C p}+\Pi_{U p}$.

According to the contract parameters, the ESCO's profit is determined by the upfront payment $\tilde{\Pi}_{C p}$ and the additional payments received or made after the realization of the energy savings $\Pi_{C}$ :

$$
\Pi_{C p}=\tilde{\Pi}_{C p}+\Pi_{C}
$$

The ESCO's profit that depends on the realization of the energy savings $\Pi_{C}$ is given 


$$
\Pi_{C}=-\alpha_{l}(G-S)^{+}+\alpha_{p}(S-T)^{+}
$$

where $(a)^{+}=\max \{a, 0\}$. In the above equation, the first term of the right-hand side is the amount the ESCO pays to the energy user when the realized saving is below the guaranteed level including the penalty and the second term is the reward payment received when the realized energy saving is above the target level.

Similarly, the energy user's profit consists of a part that is guaranteed regardless of the energy saving realization, $\tilde{\Pi}_{U p}$ and another part that will be added based on the energy savings realization $\Pi_{U}$ :

$$
\Pi_{U p}=\tilde{\Pi}_{U p}+\Pi_{U}
$$

$\tilde{\Pi}_{U p}$ is the profit level the energy user expects to get from the energy efficiency project with the energy performance contract without considering the penalty payments and the share of the savings above the target level and $\Pi_{U}$ is the energy user's profit that depends on the realization of the energy savings. $\Pi_{U}$ is given as

$$
\Pi_{U}=\left(\alpha_{l}-1\right)^{+}(G-S)^{+}+\left(1-\alpha_{p}\right)(S-T)^{+} .
$$

In Equation (5), the first term of the right-hand side is the penalty payment that is received from the ESCO when the realized saving is below the guaranteed level and the deficit is covered by the ESCO. The energy user collects a penalty if $\alpha_{l}$ is set to greater than 1 in the contract. The second term is the energy user's share of the realized saving above the target level.

By using Equations (1), (2), and (4), the profit level the energy user expected to get from the energy efficiency project with the energy performance contract without considering the penalty payments and the share of the savings above the target level, $\tilde{\Pi}_{U p}$ can be written as

$$
\tilde{\Pi}_{U p}=\mu-c-\tilde{\Pi}_{C p}+E\left[(G-S)^{+}\right]-E\left[(S-T)^{+}\right] .
$$

In the above equation, since $T \geq G, E\left[(G-S)^{+}\right]-E\left[(S-T)^{+}\right]$is always non-negative. As a result, the energy savings performance contract guarantees a profit level for the energy user that is the difference between the expected savings and the costs of the project and the ESCO'S upfront payment.

Furthermore, when the guaranteed and the target levels are set equal to each other, i.e. when $G=T, E\left[(G-S)^{+}\right]-E\left[(S-T)^{+}\right]=G-\mu$. This yields $\tilde{\Pi}_{U p}=G-c-\tilde{\Pi}_{C p}$. In other words, the energy user can guarantee a return that is the difference between the guaranteed savings level and the costs of the project and the upfront payment to the ESCO.

The reason how the energy performance contract guarantees a profit level that is above the net contribution of the energy efficiency project to the energy user is that specifying a guaranteed saving level that eliminates the downside risk and also a target level in the contract. These two conditions bring an additional profit to the energy user without any additional risk.

However, the ESCO carries a risk since its total profit can be below or above the upfront payment depending on the contract parameters. 
Figure 2. ESCO's and the energy user's profits for different energy savings realizations $(\mu=10, G=8$, $\left.T=15, \alpha_{l}=1.2, \alpha_{p}=0.72\right)$

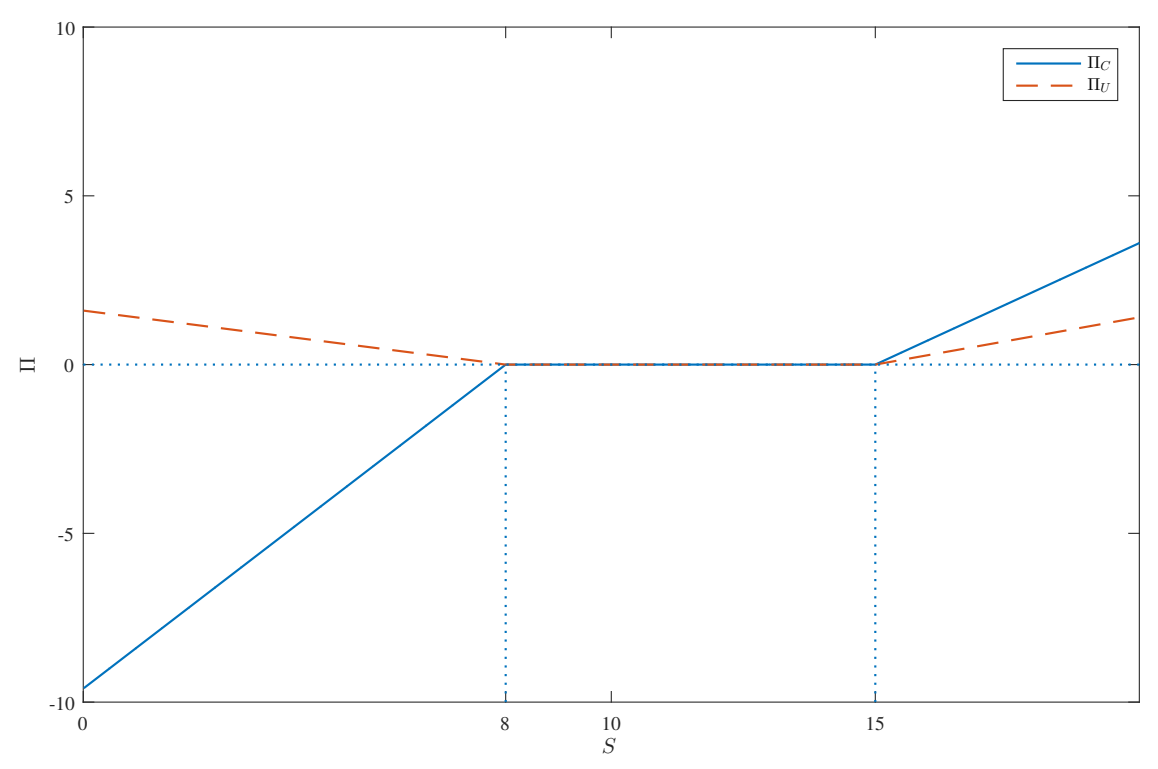

In our analysis, we focus on the profits of the ESCO and the energy user that depend on the realization of the energy savings, $\Pi_{U}$ and $\Pi_{C}$. For simplicity, we will refer $\Pi_{U}$ and $\Pi_{C}$ as the ESCO's and the energy user's profits and $\Pi_{U p}$ and $\Pi_{C p}$ as the ESCO's and the energy user's total profits respectively.

Figure 2 depicts the ESCO's and the energy user's profit for different energy saving realizations for a specific case. Note that if the energy saving is below the guaranteed level, the ESCO loses money compared to the predetermined profit level. If the energy saving is above the target level, the ESCO makes an extra profit. When the energy saving is between the guaranteed level and the target level, the ESCO does not gain or lose with respect to the initial contract. Since $S$ is a random variable, $\Pi_{C}, \Pi_{U}, \Pi_{C p}$, and $\Pi_{U p}$ are also random variables.

\section{Analysis of the Model}

The general energy savings performance contract $\left(G, T, \alpha_{l}, \alpha_{p}\right)$ covers all different contract types used between ESCOs and energy users. In our analysis, we start with evaluating the effects of the contract parameters on the ESCO's and the energy user's profits and show how these parameters should be related to each other. We will show that it is possible to use a two-parameter contract and discuss how these parameters can be determined by using the apriori information about the uncertainty regarding the energy cost savings.

The contract parameters should be determined in consideration of both parties. Otherwise determining the parameters in a way that maximizes the benefit of one party will not be accepted by the other party. We use the concept of a balanced contract to determine the parameters of the contract $\left(G, T, \alpha_{l}, \alpha_{p}\right)$ by analyzing Equations (3) and (5). 


\section{1. $\quad$ Balanced Contract}

The parameters of the energy performance contracts are usually determined by using the balanced contracts in practice, e.g. (Lee et al. 2015; Deng et al. 2015).

Lee et al. (2015) present a method to analyze the contracts between an ESCO and an energy user by arguing that the contract parameters should be chosen in a way that makes the ESCO's expected profit that depend on the realization of the energy saving zero. In other words, the ESCO'S expected total profit should be equal to the upfront fee. If the ESCO's expected profit from the part that depends on the realization of the energy saving is negative, the ESCO's expected total profit will be lower when a savings guarantee contract is offered. This will not be attractive for the ESCOs. On the other hand, the case where the expected profit is positive, i.e. the ESCO's expected total profit is higher than the upfront payment will not be preferable to the energy user since the energy user will search for a contract that yields the highest savings guarantee. As a result, the energy user will negotiate the terms of the contract with an ESCO to eliminate the expected surplus for the ESCO.

Considering the role of the ESCO in an energy savings contract with an energy user, Deng et al. (2015) analyze the energy performance contract as a zero-dollar collar option. A zero-dollar cost collar strategy combines the purchase of a put option (the right to sell the option at the strike price) and the sale of a call option (the right to buy the option) at a lower floor price. Since the put and call options are based on the same underlying asset, the zero-dollar cost collar puts an upper limit on the sale of the call option if the price falls. This strategy offsets the cost of the put option.

Accordingly, the expected benefit of the call option of the energy user it can exercise in case the energy cost saving is lower than the guaranteed level should be equal to the expected benefit of the put option of the ESCO it can exercise in case the energy cost saving is higher than the guaranteed cost saving level.

These two approaches imply that the ESCO's expected profit from the project is simply the fee it agrees when the contract is prepared, $E\left[\Pi_{C p}\right]=\tilde{\Pi}_{C p}$, and it does not make any additional expected profit from the energy savings performance contract, $E\left[\Pi_{C}\right]=0$. We refer a contract that balances the rewards and penalties for the ESCO and sets the ESCO's expected profit to zero, i.e. sets the ESCO's total expected profit to its upfront payment, a balanced contract.

Both the zero-dollar collar option approach and also the approach that sets the expected contract profit for the ESCO equal to the fee determined by the contract yield the same equality. For the balanced contract, Equation (3) yields

$$
E\left[(G-S)^{+}\right]=\beta E\left[(S-T)^{+}\right]
$$

where $\beta=\frac{\alpha_{p}}{\alpha_{l}}$. Since $\alpha_{l} \geq 1$ and $0 \leq \alpha_{p} \leq 1,0 \leq \beta \leq 1$. This equality shows that the ratio of $\alpha_{p}$ and $\alpha_{l}$ is important to obtain a balanced contract.

\subsection{Determining the Parameters of a Balanced Contract}

We determine the characteristics of the balanced contracts and determine their parameters by analyzing the properties of the equality given in Equation (7).

Depending on the values of $G$ and $T$, the equality given in Equation (7) may not be satisfied. Namely, if $E\left[(G-S)^{+}\right]>E\left[(S-T)^{+}\right]$for all values of $G$ and $T$ for a given distribution of $S$, then it is not possible to set a $\beta$ value, $0 \leq \beta \leq 1$ to balance the benefits of both parties. 


\subsubsection{Guaranteed and Target Savings Levels: $G$ and $T$}

Our first result shows that for a given guaranteed energy savings level that is less than the expected cost saving, the target savings level must be less than or equal to a threshold in order to have a balanced contract. In addition, if the guaranteed level is set at the expected cost saving level, then the target level cannot be set above the guaranteed level. In other words, in order to set a neutral zone where both parties do not get affected, the guaranteed level must be set below the expected cost savings level.

Proposition 4.1. If the guaranteed energy savings level is set to less than the expected savings level then the target savings level must also be set to less than or equal to a threshold level $G+\delta^{*}$ in order to obtain a balanced contract. That is, if $G<\mu$, there exists a threshold $\delta^{*}, 0 \leq \delta \leq \delta^{*}$ that results in a balanced contract $\left(G, G+\delta, \alpha_{l}, \beta \alpha_{l}\right)$ with $0 \leq \beta \leq 1$. Furthermore, if the guaranteed energy savings level is set equal to the expected savings level, then the target savings level must be set equal to the guaranteed service level. That is, if $G=\mu, \delta^{*}=0$, i.e. $T=G$.

The proof is given in the Appendix.

This result also shows that if the guaranteed energy level is set to 0 as in the shared savings contracts, the target level can be as high as possible. However, as the guaranteed energy level increases, the target level should decrease to have a balanced contract.

\subsubsection{ESCO's Shares in Energy Savings Surplus and Deficit: $\alpha_{p}$ and $\alpha_{l}$}

Note that Equation (7) shows that the ratio of $\alpha_{p}$ to $\alpha_{l}$ determines the relationship between $G$ and $\beta=\frac{\alpha_{p}}{\alpha_{l}}$. Accordingly, setting $\alpha_{l}=1$ to cover the deficit without any additional penalty to the ESCO and then using $\alpha_{p}$ to share the expected benefits gives the same equality given in Equation (7). In other words, only the ratio of $\alpha_{p}$ to $\alpha_{l}$ is important to achieve a balanced contract when both parties consider only the expected profits.

For a given $\beta$, setting $\alpha_{l}>1$ does not have any effect on the expected profit of the energy user while it increases the risk of losing money below the predetermined level from the contract for the ESCO ( $\operatorname{prob}(\Pi<0))$ as it will be discussed in Section 4.4. Accordingly, the contract becomes less attractive for the ESCO. This suggests, setting $\alpha_{l}=1$ is a more favorable choice to obtain a balanced contract between the ESCO and the energy user.

In practice, the target cost saving is usually set to a given multiple of the guaranteed saving. For example, it can be $25 \%$ above the guaranteed savings level to introduce a neutral zone where both the ESCO and the energy user do not get additional benefit beyond the agreed level. We define this factor as $k$ and set $T=k G$.

In other words, the four-parameter general contract $\left(G, T, \alpha_{l}, \alpha_{p}\right)$ can be specified by two parameters $G$ and $\beta$ for an exogenously given $k$ by setting $\alpha_{p}=\beta, \alpha_{l}=1$, and $T=k G$ to construct the contract $(G, k G, 1, \beta)$. 


\subsection{Effect of the Distribution of the Energy Savings on the Balanced Contract}

The results presented in this section show that the distribution of the energy savings play an important role for determining the contract parameters. If the distribution of the energy cost saving $F(s)$ is known, the condition given in Equation (7) can be used to determine the expression that relate $G$ to $\beta$. In the next part, we first analyze the cases when the energy cost saving is assumed to have uniform and normal distribution. Then we derive the equations that relate the contract parameters with each other when the energy cost saving distribution is not known but its expectation and variance are available.

\subsubsection{Uniformly Distributed Energy Saving Case}

When there is no information available about the possible energy savings resulting from a project other than the maximum saving, $M$, that can be achieved, it can be assumed that the energy saving is uniformly distributed between 0 and $M$. When $S$ is uniformly distributed between 0 and $M$, we can write

$$
\begin{gathered}
E\left[(G-S)^{+}\right]=\int_{0}^{G}(G-s) f(s) d s=\frac{G^{2}}{2 M}, \\
E\left[(S-T)^{+}\right]=\int_{T}^{M}(s-T) f(s) d s=\frac{(M-T)^{2}}{2 M} .
\end{gathered}
$$

In order to guarantee that a balanced contract can be constructed, $E\left[(G-S)^{+}\right]$must be less than or equal to $E\left[(S-T)^{+}\right]$. This condition together with Equations (8) and (9) yields the following inequality for the values of $G$ and $T$ :

$$
G \leq T \leq M-G
$$

The above inequality implies that $G \leq \frac{M}{2}$. That is the guaranteed saving level must be less than or equal to the expected cost saving as given in Proposition 1. In other words, it is not possible to reach a balanced contract if the guaranteed saving level is set to a level greater than the expected cost saving. Equivalently, as given in Proposition 1, the ratio between the target level and the guaranteed level $k=\frac{T}{G}$ can be increased up to a threshold:

$$
1 \leq k \leq \frac{M}{G}-1
$$

The above inequality shows that, when the guaranteed savings level is set to, say, $40 \%$ of the maximum savings level, the target level can be up to $50 \%$ higher compared to the guaranteed savings level. Equivalently, when the guaranteed savings level is set to $10 \%$ below the expected cost, the target level can be at most $10 \%$ above the expected cost.

Once this inequality is satisfied, Equation (7) yields an equality that sets the guaranteed service level $G$ as a fraction of the maximum energy saving $M$ for a given 
profit-sharing ratio $\beta$ :

$$
G=\frac{M \sqrt{\beta}}{1+k \sqrt{\beta}} .
$$

The above equation shows that as the ESCO's per-unit reward that depends on the performance increases, the guaranteed energy savings level should also be set to a higher level to achieve a balanced contract.

\subsubsection{Normally Distributed Energy Saving Case}

Since the realized energy saving can be affected from the combination of many independent random factors and it is expected that the deviations from the expected cost saving are equally likely, a normal distribution can also be assumed for the energy savings. When $S$ is normally distributed with the mean $\mu$ and the standard deviation $\sigma$, we can write

$$
E\left[(S-T)^{+}\right]=\sigma \eta\left(\frac{T-\mu}{\sigma}\right)
$$

where $\eta(z)=\phi(z)-z(1-\Phi(z))$ with $\phi(z)$ is the density function and $\Phi(z)$ is the distribution function of the standard normal distribution.

Similarly,

$$
E\left[(G-S)^{+}\right]=G-\mu+\sigma \eta\left(\frac{G-\mu}{\sigma}\right) .
$$

By using these definitions, Equation (7) relates the values of $G, T$, and $\beta$ through a nonlinear equality.

For the special case where $G=T$, Equation (7) yields

$$
G=\mu-\sigma(1-\beta) \eta\left(\frac{G-\mu}{\sigma}\right) .
$$

The above equation shows that the guaranteed energy saving level should be below the expectation as proven in Proposition 1. As the profit share increases the guaranteed energy savings level gets closer to the expected saving level. Furthermore, as the variability of the energy savings increases, the guaranteed savings level decreases.

Figure 3 shows the relationship between the ESCO's profit share and the guaranteed saving level for different coefficient of variations of the energy cost savings when the target level and the guaranteed saving levels are set to the same value and the distribution of the cost saving is normal. The figure shows that as the guaranteed savings level increases, the ESCO's profit share increases rapidly to yield a balanced contract between the energy user and the ESCO. Furthermore, as the variability of the cost saving increases, the ESCO's profit share should also increase to account for the additional risk that will be carried by the ESCO.

Figure 4 shows the limits for setting the target savings level for different levels of the guaranteed savings that ensure a balanced contract between the energy user 
Figure 3. Profit share of ESCO for different guaranteed savings levels (Normally distributed cost savings $\mu=1, T=G)$

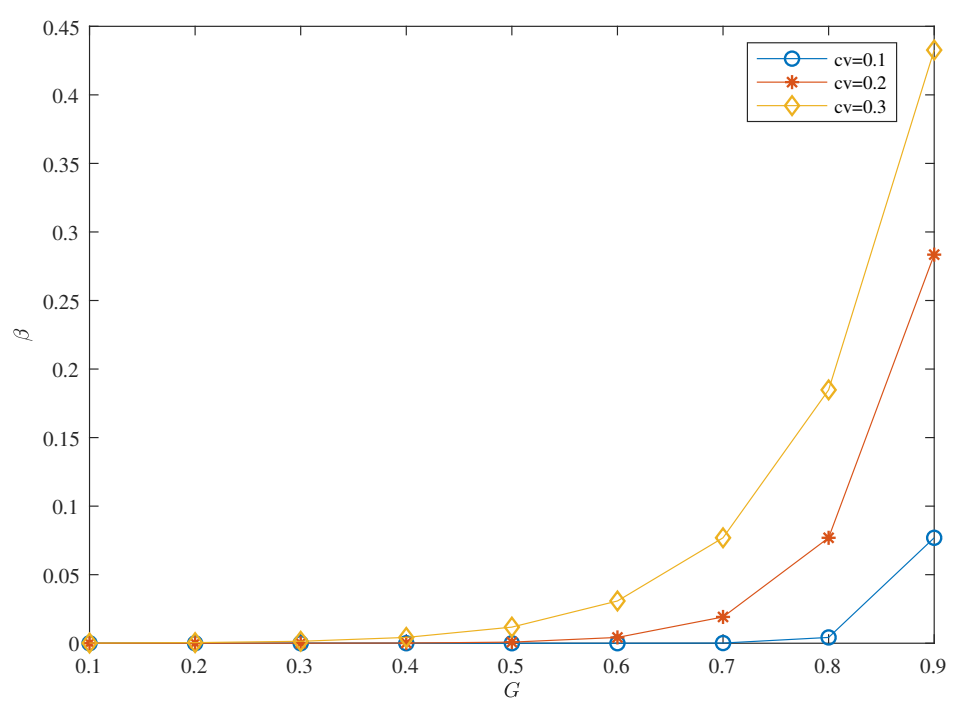

and the ESCO. When the guaranteed savings level is equal to the expected energy cost savings, the target savings level can be set to $40 \%$ above the guaranteed saving level (i.e. $T / G=1.4$ ). However, as the guaranteed saving level is set apart from the expected cost saving level, the range for the target saving level gets narrower.

\subsection{Risk Implications of the Contract Parameters on the ESCO and the Energy User}

In the above discussion, the expectation of the profits for the energy user and the ESCO was used as the main criterion to set the parameters of a balanced contract. In this section, we analyze the risk implications of the contract parameters by focusing on the probability of having profits that are less than or equal to for some given values for the energy user and the ESCO. That, we analyze the risk measures $\operatorname{prob}\left(\Pi_{C} \leq \pi\right)$ and $\operatorname{prob}\left(\Pi_{U} \leq \pi\right)$.

Since $\Pi_{C p}=\tilde{\Pi}_{C p}+\Pi_{C}$, this risk measure can be interpreted as the downside risk for the parties when $\pi<0$. The risk that the ESCO's profit is less than the upfront payment set in the contract is $\operatorname{prob}\left(\Pi_{C p} \leq \tilde{\Pi}_{C p}=\operatorname{prob}\left(\Pi_{C} \leq 0\right)\right.$.

The probability that the ESCO's profit is less than or equal to a given value $\pi$ is determined from the probability distribution function of the energy saving as

$$
\operatorname{prob}\left(\Pi_{C} \leq \pi\right)=\left\{\begin{array}{lll}
F\left(G+\frac{\pi}{\alpha_{l}}\right) & \text { if } & 0>\pi \\
F\left(T+\frac{\pi}{\alpha_{p}}\right) & \text { if } & 0 \leq \pi
\end{array} .\right.
$$

As an example, Figure 5 depicts the distribution of energy cost saving and the ESCO's profit when the distribution of the energy cost saving is normal. Note that setting the target saving level apart from the guaranteed saving level improves the probability that the ESCO's profit is higher than a given value. 
Figure 4. Target savings levels for feasible contracts for different guaranteed savings levels (Normally distributed cost savings $\mu=1, \sigma=0.2$ )

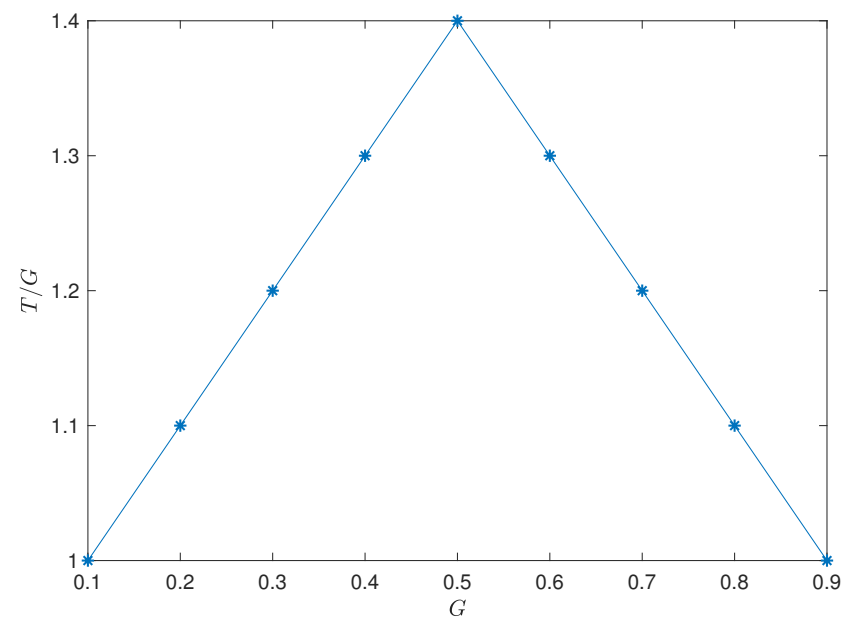

Figure 5. Distribution of the energy savings and the ESCO's profit (Normally distributed cost savings $\mu=$ $\left.10.625, c v=0.2, G=10, T=12.5, \alpha_{l}=1, \alpha_{p}=0.8\right)$
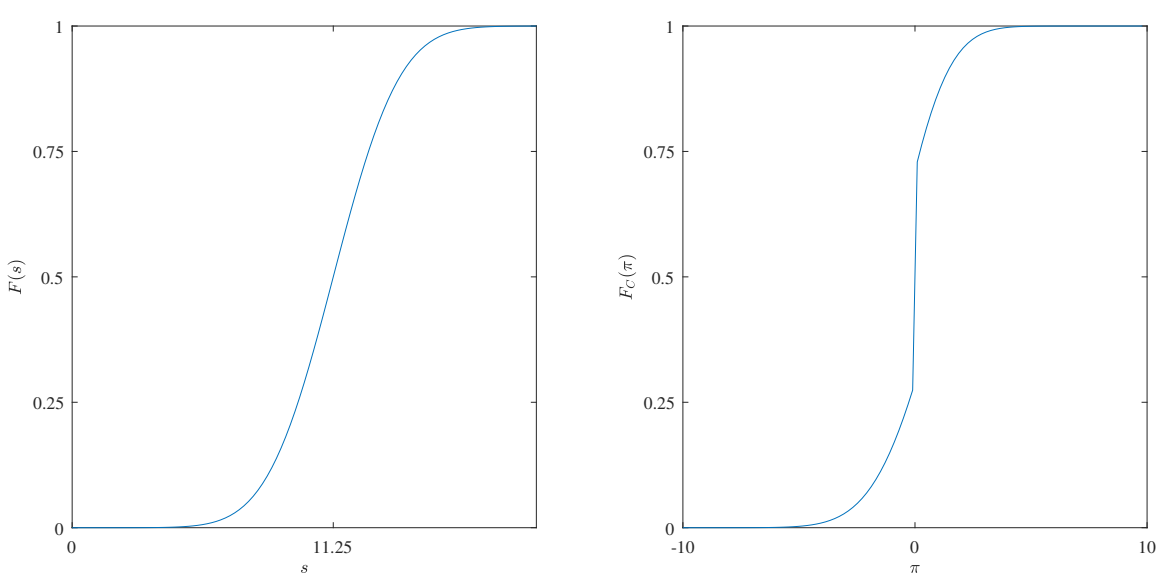
Similarly, the probability that the energy user's profit is less than or equal to a given value is given as

$$
\operatorname{prob}\left(\Pi_{U} \leq \pi\right)=\left\{\begin{array}{lll}
0 & \text { if } & 0>\pi \\
F(G)-F\left(G-\frac{\pi}{\alpha_{l}-1}\right)+F\left(T+\frac{\pi}{1-\alpha_{p}}\right) & \text { if } & 0 \leq \pi \leq \frac{G}{\alpha_{l}-1} \\
F\left(T+\frac{\pi}{1-\alpha_{p}}\right) & \text { if } & \frac{G}{\alpha_{l}-1}<\pi
\end{array}\right.
$$

when $\alpha_{l}>1$. If the ESCO is required to cover the deficit when the realized savings level is lower than the guaranteed level without any additional penalty, i.e. when $\alpha_{l}=1$, the probability that the energy user's profit is less than or equal to a given value is given, as

$$
\operatorname{prob}\left(\Pi_{U} \leq \pi\right)=\left\{\begin{array}{lll}
0 & \text { if } & 0>\pi \\
F\left(T+\frac{\pi}{1-\alpha_{p}}\right) & \text { if } & 0 \leq \pi
\end{array} .\right.
$$

Equations (16) and (17) allow us to determine the probability distributions for the profits of the energy user and the ESCO. Note that according to this result, the probability of getting a profit level that is below the predetermined profit level that does not depend on the realization of the energy savings $(\pi=0)$ is the same for the service provider and for the customer:

$$
\begin{aligned}
& \operatorname{prob}\left(\Pi_{U} \leq 0\right)=\operatorname{prob}\left(\Pi_{U p} \leq \tilde{\Pi}_{U p}\right)=F(T) \\
& \operatorname{prob}\left(\Pi_{C} \leq 0\right)=\operatorname{prob}\left(\Pi_{C p} \leq \tilde{\Pi}_{C p}\right)=F(T)
\end{aligned}
$$

for all values of $\alpha_{l}$ and $\alpha_{p}$. Note that this probability is determined by the target savings level and the distribution of the cost savings.

Equations (16) and (17) show that using a target level $T \geq G$ improves the probability that the profit is above a specific non-negative level for both parties. So, both parties would prefer contracts that set the guaranteed and target energy saving levels apart from each other among the ones that have yield the same expected profit if they use a probabilistic criterion in addition to their expected profit.

Our next result shows that the contract can be designed to make the probabilities of achieving profits above the given levels for the energy user and the ESCO equal to each other. This is achieved by setting the ESCO's share of the realized savings above the target level $\alpha_{p}$ depending on the target levels considered by the ESCO and the energy user. The differences between the target profit levels used to determine these probability measures reflect the possible differences between the risk expectations of the ESCO and the energy user.

Proposition 4.2. The ESCO's share of the realized savings above the target level, $\alpha_{p}$ should be set to $\frac{\pi_{U}}{\pi_{U}+\pi_{C}}$ in order to make the probabilities of achieving profits above $\pi_{U}$ and $\pi_{C}$ equal to each other for the energy user and the ESCO respectively. That is, $\operatorname{prob}\left(\Pi_{U} \geq \pi_{U}\right)=\operatorname{prob}\left(\Pi_{C} \geq \pi_{C}\right), \pi_{U}>0, \pi_{C}>0$ when $\alpha_{p}=\frac{\pi_{U}}{\pi_{U}+\pi_{C}}$.

The proof is given in the Appendix. 
The above proposition shows that as the target profit level of the energy user increases while the target profit level of the ESCO stays the same, $\alpha_{p}$ is set closer to 1 in order to use this probabilistic criterion to construct the contract. Similarly, as the target profit level of the ESCO increases while the target profit level of the ESCO stays the same, $\alpha_{p}$ is set closer to 0 . After this consideration, the guaranteed savings level and the target level should be set by considering the distribution of the savings as discussed in Section 4.3.

\subsection{Profit Variability Depending on Contract Parameters}

In addition to the probabilistic criterion, the variance of the profits can also be used as a measure of the volatility of the performance for the energy user and the ESCO. The variance of the ESCO's profit can be determined from the distribution function:

$$
\operatorname{Var}\left[\Pi_{C}\right]=\int_{-G \alpha_{l}}^{\infty}\left(1-\operatorname{prob}\left(\Pi_{C} \leq \pi\right)\right) \pi d \pi-E^{2}\left[\Pi_{C}\right] .
$$

For the case where the energy cost saving is uniformly distributed between 0 and $M$, the variance of the cost saving of the ESCO is given as

$$
\operatorname{Var}\left[\Pi_{C}\right]=-G^{2} \alpha_{l}^{2}\left(\frac{G}{3 M}+1\right)+(M-T)^{2} \alpha_{p}^{2}\left(\frac{2 M+T}{3 M}+1\right)-E^{2}\left[\Pi_{C}\right] .
$$

When the parameters of the contract are set optimally, Equation (7) is satisfied and therefore $E\left[\Pi_{C}\right]=0$. Accordingly, the variance of the profit of the ESCO for the optimal values of the contract is

$$
\operatorname{Var}\left[\Pi_{C}\right]=a^{2} M^{2} \alpha_{l}^{2}\left(4 \beta+\frac{a(6 k-1)}{3}\right)
$$

where $a=\frac{\sqrt{\beta}}{1+k \sqrt{\beta}}$ and $k=\frac{T}{G}$. The above equation shows that the variability of the ESCO's profit increases with $\beta$.

For the case where the cost saving is normal, a closed-form expression for the variance of the profit is not available. However, Equation (21) can be used to determine the variance for given values of the contract parameters.

\section{Distribution-free Determination of the Contract Parameters}

Energy cost savings depend on many random factors including uncertainty in energy prices, uncertainty in energy usage, and uncertainty in the performance of the energy efficiency measures when they are applied to a particular building or a plant (Tan and Yavuz 2015). As a result, estimating energy savings is a challenging task (Lee et al. 2013).

In this part, we present an approach to determine the contract parameters when the distribution of the energy cost savings, $F(s)$ is not known but its expectation and variance are available. 
In this case, the ESCO and the energy user can set the contract parameters to make it sure that the contract is as close as possible to the balanced contract for all distributions. In other words, for the worst distribution of $S$, the expected reward that will be received from the realized energy savings above the target level and the expected cost of guaranteeing a level of energy savings including the penalty are as close as possible for the ESCO. In order to achieve this objective, they can solve the following problem to determine $G$ and $T$ for a given value of $\beta$ :

$$
\min _{G, T}\left|E\left[(G-S)^{+}\right]-\beta E\left[(S-T)^{+}\right]\right|
$$

Our main result shows that the guaranteed energy saving level and the parameter $\beta$ can be set by using only the expectation and the standard deviation of the energy saving.

Proposition 5.1. The guaranteed energy savings level and the target energy savings level should be set to $G=T=\mu-\frac{1-\beta}{2 \sqrt{\beta}} \sigma$ in order to make the ESCO's expected profit from the contract as close as possible to its upfront payment and operate an energy savings performance contract that is as close as possible to a balanced contract for all distributions of the energy savings.

The proof is given in the Appendix.

In words, when the distribution of the energy cost saving is not known, the guaranteed energy saving level should be set to a level lower than the expected energy savings level depending on the standard deviation of the energy savings and the parameter $\beta$. Furthermore, the target savings level must be equal to the guaranteed savings level.

Figure 6 depicts the guaranteed energy cost savings values for different $\beta$ ratios calculated by using the normal distribution, the uniform distribution, and the distribution-free approximation. The figure shows that determining the profit share by using the distribution-free approximation yields values that are in between the ones obtained by the uniform and the normal distributions when the guaranteed cost saving is above approximately 0.4 . When the guaranteed energy cost savings level is below this point, using the normal distribution gives an expected profit for ESCO above the upfront payment that is very close to zero. Using the uniform and the distribution-free approximation yield non-zero but small values that are close to each other.

When the optimal $G$ value is used in a balanced contract, the expected profit of the energy user from the project will be

$$
E\left[\Pi_{U p}\right] \leq \tilde{\Pi}_{U p}+\frac{1}{2}(1-\beta) \sqrt{\beta} \sigma .
$$

In other words, the contract generates a surplus of at most $\frac{1}{2}(1-\beta) \sqrt{\beta} \sigma$ above the pre-determined level for the energy user.

\subsection{Distribution-free Simple Energy Performance Contract}

In order to determine the contract $\left(G, T, \alpha_{l}, \alpha_{p}\right)$, all four parameters must be specified. As discussed earlier, we can set $\alpha_{l}=1$ and $\alpha_{p}=\beta$ to achieve a balanced contract. 
Figure 6. ESCO's profit share for different guaranteed savings levels $(\mu=1, \sigma=0.3, T=G)$

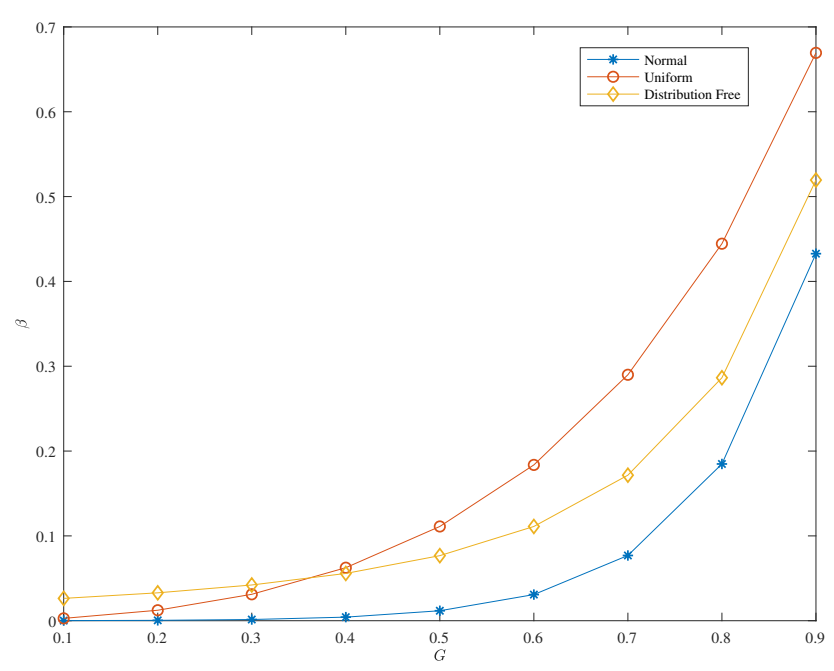

Furthermore, Proposition 3 sets $G=T$ and Equation (38) relates $G$ to $\beta$.

Our final result gives a simple formula to set a balanced contract by determining the value of $\alpha_{p}$. In order to derive this result, we make the assumption that the ESCO and the user can use an additional criterion to equate the probability of making a profit above a certain level for both parties, i.e., $\operatorname{prob}\left(\Pi_{U}>\pi\right)=\operatorname{prob}\left(\Pi_{C}>\pi\right)$. This condition also yields the same down-side risk for both parties, i.e. $\operatorname{prob}\left(\Pi_{U} \leq\right.$ $\pi)=\operatorname{prob}\left(\Pi_{C} \leq \pi\right)$.

In this case, the next result yields a rule of thumb for setting the guaranteed energy savings level based on the expectation and the standard deviation of the energy saving.

Proposition 5.2. When the distribution of the energy savings is not known, a simple contract $\left(G, G, 1, \frac{1}{2}\right)$ that sets the guaranteed energy savings level to $G=\mu-\frac{\sqrt{2}}{4} \sigma$ and the shares of the savings above the guaranteed level for the energy user and the ESCO to $\frac{1}{2}$ minimizes the difference between the expected reward and penalty for the ESCO and makes the ESCO's expected profit from the contract as close as possible to its upfront payment for the worst distribution of the energy savings. This contract also makes the probability of having a total profit that is below the predetermined levels that do not depend on the realization of the energy savings, and the probability of making a profit that is higher than a given value the same for the energy user and the ESCO.

The proof is given in the Appendix.

The above results show that the energy savings performance contract can be set completely by using only the mean and the standard deviation of the energy saving if there is no other information regarding the distribution of the energy savings and risk preferences of the energy user and the ESCO. As a result, this rule of thumb simplifies the contract design by using only the mean and the standard deviation of the anticipated energy cost savings.

Note that the assumption on using the same downside risk probabilities for both the ESCO and the energy user is made to get a simple contract in case no additional information is available. If additional information is available, the coefficient that will 
be multiplied with the standard deviation can be adjusted accordingly by first setting $\alpha_{p}$ and $\alpha_{l}$ following Equations (16), (17) and (18) and then using Proposition 5.1.

Proposition 5.2 shows that if the mean and the standard deviation of the energy savings can be estimated, setting a contract, $(G, G, 1,0.5)$, where the ESCO guarantees an energy saving level that is $\frac{\sqrt{2}}{4} \approx 0.35$ standard deviation below the expected saving yields a balanced contract. According to this contract, the ESCO agrees covering all the losses if the energy saving is lower than this level and the savings above the guaranteed level is shared equally between the ESCO and the energy user.

\subsection{Performance of the Distribution-free Simple Contract}

Let us consider the performance of the distribution-free simple energy performance contract when the energy saving distributed is uniform and normal.

For uniformly distributed energy saving between 0 and $M$, the expected saving is $\mu=\frac{M}{2}$ and the standard deviation of the energy saving is $\sigma=\frac{M}{2 \sqrt{3}}$. Therefore, the simple contract yields a guaranteed saving level of $G=\mu-\frac{\sqrt{2}}{4} \sigma=\left(\frac{1}{2}-\frac{\sqrt{2}}{8 \sqrt{3}}\right) M$ that is approximately equal to $G=0.4 M$.

In other words, the distribution free simple contract sets the guaranteed savings level to $40 \%$ of the maximum savinsg level when the distribution of the energy savings is uniform. In this case Equations (8) and (9) yield the expected profit for the ESCO $E\left[\Pi_{C}\right]=0.01 M=0.035 \sigma$ and $E\left[\Pi_{U}\right]=0.09 M=0.31 \sigma$. The probability of getting a total profit that is less than or equal to the pre-determined level that does not depend on the realization of the energy savings, $\operatorname{prob}\left(\Pi_{U} \leq 0\right)=\operatorname{prob}\left(\Pi_{C} \leq 0\right)$ is 0.4 when the distribution-free simple contract is used, and the energy saving is uniformly distributed.

When the energy saving is normally distributed with mean $\mu$ and standard deviation $\sigma$, the simple contract that uses $\mu$ and $\sigma$ but not the distribution sets the guaranteed energy saving level at $G=\mu-\frac{\sqrt{2}}{4} \sigma$.

In this case, Equations (13) and (14) yield the expected profits for the ESCO and the energy user as $E\left[\Pi_{C}\right]=0.05 \sigma$ and $E\left[\Pi_{U}\right]=0.3 \sigma$. The probability of getting a profit that is less than or equal to the pre-determined level, $\operatorname{prob}\left(\Pi_{U} \leq 0\right)=\operatorname{prob}\left(\Pi_{C} \leq\right.$ $0)=0.36$ when the distribution-free simple contract is used, and the energy saving is normally distributed.

This comparison shows that the distribution-free simple contract yields similar expected profit for the energy user, $0.31 \sigma$ vs. $0.3 \sigma$ for the uniformly and normally distributed energy savings respectively. Similarly, when the distribution-free simple contract is used, the expected profit for the ESCO is not zero as the optimal balanced contract would give; but it is small: $0.035 \sigma$ vs. $0.05 \sigma$ for the uniformly and normally distributed energy savings respectively.

Since the distribution-free contract sets the guaranteed savings level by using a conservative criterion, the guaranteed savings level set by the distribution-free contract will be lower compared to the level resulting from the contract determined by using the full savings distribution information. As a result, the distribution-free contract will yield a higher expected profit for the energy user and a lower probability of losing money below the pre-determined profit level for the ESCO. Both of these outcomes are preferable for the energy user and the ESCO. We will investigate these results through a set of numerical experiments in the following part. 


\section{Numerical Results}

In this part, we investigate the effects of distribution-free determination of the contract parameters and also the effects of the errors in the estimation of the expectation and the standard deviation of the energy savings on the guaranteed energy savings level, the expected profits, and the probability of having a non-positive profit for the ESCO and the energy user.

\subsection{Experimental Setup}

In our experimental setup, we generate the realized energy savings from a threeparameter Weibull distribution. This distribution allows us setting the expectation and the standard deviation of the energy savings to the desired values and also using the third parameter to analyze the effect of the shape of the distribution on the performance of the contract. The probability density function of the three-parameter Weibull distribution is

$$
f(s)=\frac{\alpha}{\gamma}\left(\frac{s-\eta}{\gamma}\right)^{\alpha-1} e^{-\left(\frac{s-\eta}{\gamma}\right)^{\alpha}}
$$

The expectation and the variance of the energy saving are given as

$$
\begin{gathered}
E[S]=\eta+\gamma \Gamma\left(\frac{1}{\alpha}+1\right) \\
\operatorname{Var}[S]=\gamma^{2}\left[\Gamma\left(\frac{2}{\alpha}+1\right)-\Gamma^{2}\left(\frac{1}{\alpha}+1\right)\right]
\end{gathered}
$$

where $\Gamma($.$) is the gamma function.$

We normalize the expected savings level to 1 , set the standard deviation to 4 different values $\sigma \in\{0.1,0.3,0.5,0.8,1\}$, and set the shift variable $\eta$ to 4 different values: $\eta \in\{0,0.3,0.4,0.5\}$. For each value of $\eta$, we determine the $\alpha$ and $\gamma$ parameters from Equations (27) and (28) in order to have the desired $\mu$ and $\sigma$. Figure 7 depicts four different probability density functions with the same mean and the standard deviation for different values of $\eta$.

\subsection{Performance of the Distribution-Free Simple Contract with Full Information on the Mean and the Standard Deviation of the Energy Saving}

We first evaluate the performance of the simple contract $(G, G, 1,0.5)$ with $G=$ $\mu-\frac{\sqrt{2}}{4} \sigma$. The optimal guaranteed energy savings level when the full distributional information is available is determined from Equation (7) with $\beta=0.5, T=G$ and the probability distribution function of the Weibull distribution with the given parameters. The expected profit and the probability of loss are determined from the Weibull distribution for the given energy savings level set by the distribution-free simple contract 
Figure 7. Weibull probability density functions for $\mu=1$ and $\sigma=0.5$ for $\eta \in\{0,0.3,0.4,0.5\}$

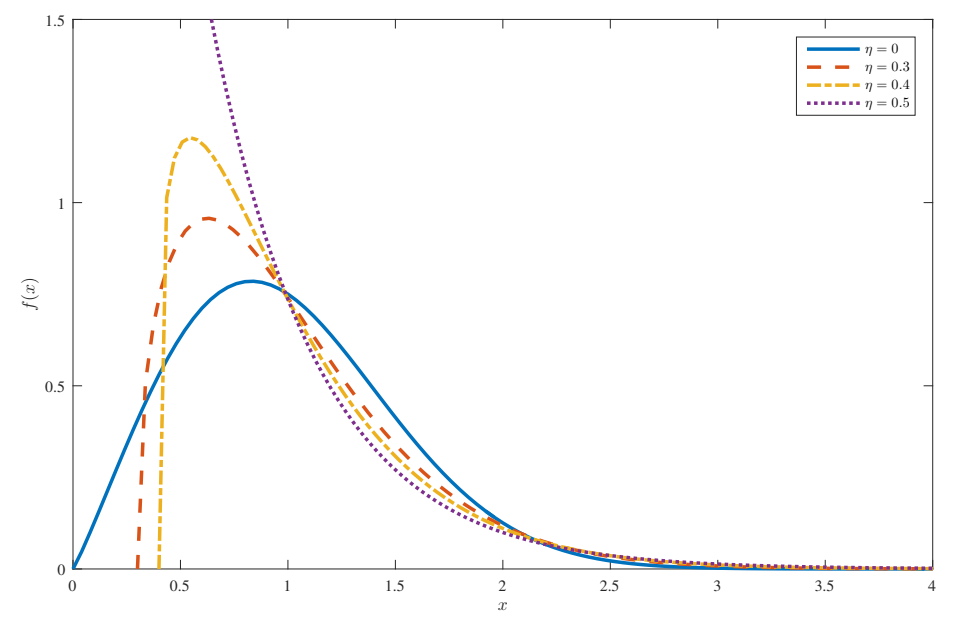

and the balanced contract with the full distributional information.

Figure 8 depicts the average guaranteed savings level resulting from the distributionfree simple contract and the guaranteed saving level determined from the optimal balanced contract with the full distributional information for different standard deviation of the energy saving. The figure supports the following observation:

Observation 6.1. The distribution-free simple contract sets the guaranteed savings level lower compared to the level resulting from the full information solution.

As described in proof of Proposition 5.2, when the exact distribution of the energy saving is not available, upper-bounds for the expected profits are used as an approximation to determine the guaranteed savings level. Consequently, the approximate expected profit will be higher than the actual profit for a given guaranteed savings level. Equivalently, the approximate profit with a lower guaranteed savings level can be equal to the exact expected profit with a higher guaranteed savings level. As a result, optimizing the approximate profit leads to a lower guaranteed savings level compared to the level that is obtained with the exact distribution.

Table 1 shows the percentage difference of the guaranteed saving level resulting from the distribution-free simple contract compared to its value determined from the optimal balanced contract with the full distributional information. The table shows that the distribution-free simple contract yields a guaranteed saving level that is on average $8 \%$ lower than the guaranteed saving level resulting from the exact valuation of the optimal balanced contract with the full distributional information.

Setting the guaranteed saving level lower compared to the value resulting from the exact distribution yields a higher expected profit for the energy user when the fee that will be paid to the ESCO does not change with the guaranteed savings levels and a lower probability of losing money below the predetermined level for the ESCO.

Table 2 gives the percentage difference of the user's expected profit resulting from the distribution-free simple contract compared to the user's expected profit from the optimal balanced contract with the full distributional information. Table 2 supports the following observation: 
Figure 8. Average guaranteed savings level determined by using the simple contract and the optimal balanced contract

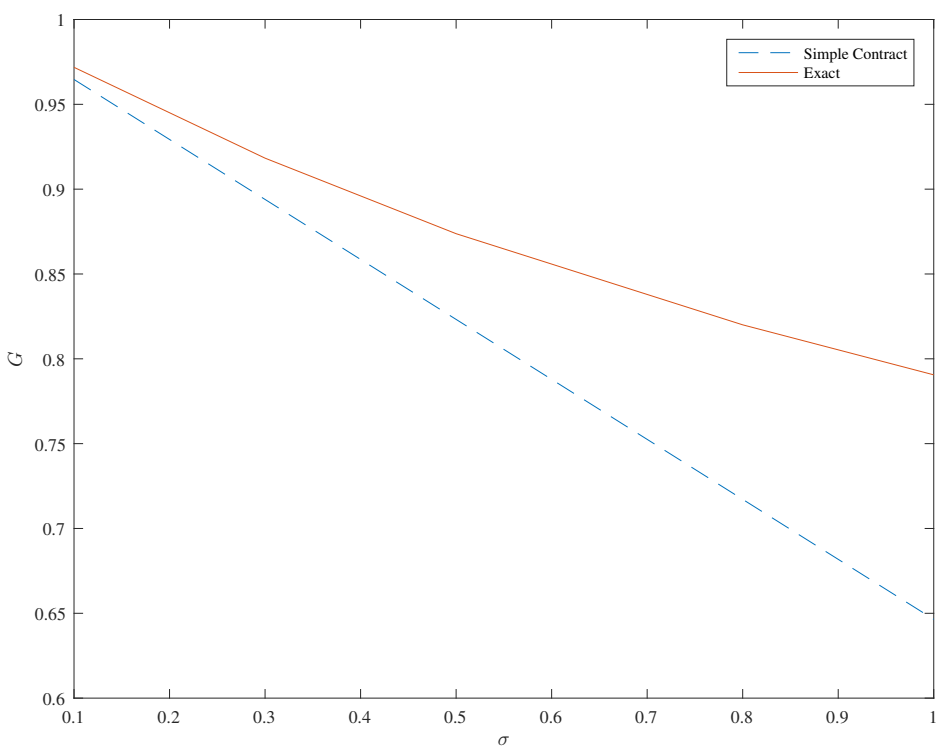

Table 1. Percentage difference of the guaranteed savings level resulting from the distribution-free simple contract compared to its value determined from the optimal balanced contract with the full distributional information

\begin{tabular}{r|rrrr|r}
$\sigma \backslash \eta$ & 0.0 & 0.3 & 0.4 & 0.5 & Avg. \\
\hline 0.1 & $-0.7 \%$ & $-0.7 \%$ & $-0.7 \%$ & $-0.7 \%$ & $-0.7 \%$ \\
0.3 & $-2.4 \%$ & $-2.6 \%$ & $-2.7 \%$ & $-2.9 \%$ & $-2.6 \%$ \\
0.5 & $-4.8 \%$ & $-5.6 \%$ & $-6.1 \%$ & $-6.6 \%$ & $-5.8 \%$ \\
0.8 & $-10.4 \%$ & $-12.3 \%$ & $-13.2 \%$ & $-14.2 \%$ & $-12.5 \%$ \\
1.0 & $-15.4 \%$ & $-17.9 \%$ & $-19.0 \%$ & $-20.5 \%$ & $-18.2 \%$ \\
\hline Avg. & $-6.7 \%$ & $-7.8 \%$ & $-8.3 \%$ & $-9.0 \%$ & $-7.8 \%$
\end{tabular}


Table 2. Percentage difference of the energy user's expected profit resulting from the distribution-free simple contract compared to the energy user's expected profit from the optimal balanced contract with the full distributional information

\begin{tabular}{r|rrrr|r}
$\sigma \backslash \eta$ & 0.0 & 0.3 & 0.4 & 0.5 & Avg. \\
\hline 0.1 & $8.5 \%$ & $8.3 \%$ & $8.3 \%$ & $8.2 \%$ & $8.3 \%$ \\
0.3 & $8.2 \%$ & $8.5 \%$ & $8.9 \%$ & $9.5 \%$ & $8.8 \%$ \\
0.5 & $8.9 \%$ & $10.3 \%$ & $11.3 \%$ & $12.6 \%$ & $10.8 \%$ \\
0.8 & $11.0 \%$ & $13.8 \%$ & $15.5 \%$ & $18.2 \%$ & $14.6 \%$ \\
1.0 & $12.6 \%$ & $16.4 \%$ & $18.9 \%$ & $23.1 \%$ & $17.8 \%$ \\
\hline Avg. & $9.8 \%$ & $11.5 \%$ & $11.5 \%$ & $12.6 \%$ & $12.1 \%$
\end{tabular}

Observation 6.2. Using the distribution-free simple contract yields a higher expected profit for the energy user.

Since the distribution-free simple contract sets the guaranteed savings level lower compared to the optimal savings level with the full information, the resulting contract is not completely balanced. Using a lower guaranteed savings level for the same fee increases the expected profit of the energy user as indicated by Equation (5).

The average percentage difference of the expected profit of the energy user resulting from the distribution-free contract and the full-information contract is around $12 \%$. Namely, the distribution-free simple contract yields $12 \%$ higher profit for the energy user compared to its profit if the guaranteed savings level is set by using the full distributional information on the energy cost savings.

Table 3 gives the percentage difference between the probability that the ESCO's total profit is lower than the upfront payment, $\operatorname{prob}\left(\Pi_{C} \leq 0\right)$, when it is determined by using the distribution-free simple contract and its value when it is determined with the full distributional information. Table 3 yields the following observation:

Observation 6.3. The distribution-free simple contract yields a lower probability of losing money for the ESCO.

The probability of losing money for the ESCO depends on the distribution of the energy savings as given in Equation (19): $\operatorname{prob}\left(\Pi_{U} \leq 0\right)=F(G)$. As a result, when the guaranteed savings level is set to a lower level as given in Observation 6.1, the probability of losing money for the ESCO also decreases.

The average percentage difference of the probability of losing money compared to the pre-determined fee, for the ESCO resulting from the distribution-free contract and the full-information contract is around $-11 \%$. That is, using the distribution-free simple contract yields $11 \%$ lower probability of getting a profit that is lower than the pre-determined fee for the ESCO.

\subsection{Performance of the Distribution-Free Simple Contract with the Estimated Mean and the Standard Deviation of the Energy Saving}

We now investigate the performance of the distribution-free simple contract when the expectation and the variance of the energy savings are estimated with error. 
Table 3. Percentage difference between the probability that the ESCO's total profit is less than or equal to the upfront payment ( $\operatorname{prob}\left(\Pi_{C} \leq 0\right)$ when it is determined by using the distribution-free simple contract and its value when it is determined with the full distributional information.

\begin{tabular}{r|rrrr|r}
$\sigma \backslash \eta$ & 0.0 & 0.3 & 0.4 & 0.5 & Avg. \\
\hline 0.1 & $-7.0 \%$ & $-6.9 \%$ & $-6.9 \%$ & $-6.8 \%$ & $-6.9 \%$ \\
0.3 & $-6.8 \%$ & $-7.2 \%$ & $-7.5 \%$ & $-8.0 \%$ & $-7.4 \%$ \\
0.5 & $-7.5 \%$ & $-8.8 \%$ & $-9.6 \%$ & $-10.9 \%$ & $-9.2 \%$ \\
0.8 & $-9.4 \%$ & $-12.0 \%$ & $-13.7 \%$ & $-16.7 \%$ & $12.9 \%$ \\
1.0 & $-10.9 \%$ & $-14.7 \%$ & $-17.5 \%$ & $-22.9 \%$ & $-16.5 \%$ \\
\hline Avg. & $-8.3 \%$ & $-9.9 \%$ & $-11.0 \%$ & $-13.1 \%$ & $-10.6 \%$
\end{tabular}

We consider different cases depending on how much the estimates of the expectation and the standard deviation, $\hat{\mu}$ and $\hat{\sigma}$ differ from the exact values of $E[S]=\mu$ and $\operatorname{Var}[S]=\sigma^{2}$. We set $\hat{\mu}=\mu\left(1 \pm \epsilon_{\mu}\right)$ and $\hat{\sigma}=\mu\left(1 \pm \epsilon_{\sigma}\right)$ for $\epsilon_{\mu} \in\{0,0.05,0.10,0.15,0.20\}$ and $\epsilon_{\sigma} \in\{0,0.05,0.10,0.15,0.20\}$.

We construct the balanced contract by using Proposition 4 and the estimated values of the expectation and the standard deviation of the energy saving. Accordingly, we set $\beta=\alpha_{p}=0.5$, and $G=T=\hat{\mu}-\frac{\sqrt{2}}{4} \hat{\sigma}$.

With this contract, for a total of 1620 different cases for different values of $\eta, \sigma, \epsilon_{\mu}$, and $\epsilon_{\sigma}$, we determine the guaranteed energy savings level set by the distribution-free simple contract with $\hat{\mu}$ and $\hat{\sigma}$ and the resulting the expected profit for the energy user, and the probability of getting a profit below the pre-determined fee for the ESCO by using the exact distribution with the actual values of $\mu$ and $\sigma$. For each case, we also determine the performance of the simple contract with the correct values of $\mu$ and $\sigma$ and the performance of the balanced contract with the correct values of $\mu$ and $\sigma$ and also the exact distribution of the energy savings.

Table 4 shows the percentage difference of the guaranteed saving level resulting from the distribution-free simple contract with the estimated values of the mean and the standard deviation of the energy savings compared to its value determined from the optimal balanced contract with the full distributional information. The table shows that the distribution-free simple contract yields a guaranteed saving level that is on average $8 \%$ lower than the guaranteed saving level resulting from the exact valuation of the optimal balanced contract with the full distributional information. This shows that Observation 6.1 is still valid when the mean and standard deviation are estimated with error. Table 4 yields the following observation:

Observation 6.4. Underestimating the expectation and overestimating the standard deviation of the energy saving have more effect on the guaranteed savings level compared to overestimating the expectation and underestimating the standard deviation.

The simple contract sets a lower guaranteed savings level compared to the level with the full information when the mean and the standard deviation of the energy savings are known exactly as discussed in Observation 6.1. When the mean is underestimated and the standard deviation of the energy savings is overestimated, the guaranteed savings level set by the simple contract, $G=T=\hat{\mu}-\frac{\sqrt{2}}{4} \hat{\sigma}$ will be even lower than the level with the full information. However, overestimating the mean and underestimating the standard deviation make the level set by the simple contract closer to the level with 
the full information. As a result, underestimating the expectation and overestimating the standard deviation of the energy saving have more effect on the guaranteed savings level.

If the distribution of the energy saving is known but its mean and the expectation are estimated with an error and the guaranteed saving level is determined with the estimates from the distribution, the average percentage difference between the guaranteed energy saving level between the estimated contract and the exact contract will be close to zero. This shows that the distribution of the energy saving has an important effect on the guaranteed savings level.

Table 4. Percentage difference of the guaranteed savings level resulting from the distribution-free simple contract with the estimated mean and the standard deviation compared to its value determined from the optimal balanced contract with the full distributional information

\begin{tabular}{r|rrrrrrrrr|r}
$\epsilon_{\mu} \backslash \epsilon_{\sigma}$ & -0.20 & -0.15 & -0.10 & -0.05 & 0.00 & 0.05 & 0.10 & 0.15 & 0.20 & Avg. \\
\hline-0.20 & $-26 \%$ & $-28 \%$ & $-29 \%$ & $-30 \%$ & $-31 \%$ & $-32 \%$ & $-33 \%$ & $-34 \%$ & $-36 \%$ & $-31 \%$ \\
-0.15 & $-21 \%$ & $-22 \%$ & $-23 \%$ & $-24 \%$ & $-25 \%$ & $-26 \%$ & $-28 \%$ & $-29 \%$ & $-30 \%$ & $-25 \%$ \\
-0.10 & $-15 \%$ & $-16 \%$ & $-17 \%$ & $-18 \%$ & $-19 \%$ & $-21 \%$ & $-22 \%$ & $-23 \%$ & $-24 \%$ & $-19 \%$ \\
-0.05 & $-9 \%$ & $-10 \%$ & $-11 \%$ & $-13 \%$ & $-14 \%$ & $-15 \%$ & $-16 \%$ & $-17 \%$ & $-18 \%$ & $-14 \%$ \\
0.00 & $-3 \%$ & $-5 \%$ & $-6 \%$ & $-7 \%$ & $-8 \%$ & $-9 \%$ & $-10 \%$ & $-11 \%$ & $-13 \%$ & $-8 \%$ \\
0.05 & $2 \%$ & $1 \%$ & $0 \%$ & $-1 \%$ & $-2 \%$ & $-3 \%$ & $-5 \%$ & $-6 \%$ & $-7 \%$ & $-2 \%$ \\
0.10 & $8 \%$ & $7 \%$ & $6 \%$ & $5 \%$ & $4 \%$ & $2 \%$ & $1 \%$ & $0 \%$ & $-1 \%$ & $4 \%$ \\
0.15 & $14 \%$ & $13 \%$ & $12 \%$ & $10 \%$ & $9 \%$ & $8 \%$ & $7 \%$ & $6 \%$ & $5 \%$ & $9 \%$ \\
0.20 & $20 \%$ & $18 \%$ & $17 \%$ & $16 \%$ & $15 \%$ & $14 \%$ & $13 \%$ & $12 \%$ & $10 \%$ & $15 \%$ \\
\hline Avg. & $-3 \%$ & $-5 \%$ & $-6 \%$ & $-7 \%$ & $-8 \%$ & $-9 \%$ & $-10 \%$ & $-11 \%$ & $-13 \%$ & $-8 \%$
\end{tabular}

Table 5 gives the percentage difference of the energy user's expected profit resulting from the distribution-free simple contract with the estimated values of the mean and the standard deviation of the energy savings compared to the user's expected profit from the optimal balanced contract with the full distributional information. Table 5 shows that using the distribution-free simple contract yields a higher expected profit for the energy user. This shows that Observation 6.2 is still valid when the expectation and the variance of the energy saving are estimated with error. The average percentage difference of the expected profit of the energy user resulting from the distributionfree contract and the full-information contract is around 24\%. Table 5 supports the following observation:

Observation 6.5. Underestimating the expectation and overestimating the standard deviation of the energy saving yield a much higher deviation for the expected profit for the energy user compared to the effect of overestimating the expectation and underestimating the standard deviation.

Since underestimating the expectation and overestimating the standard deviation of the energy saving yield a higher deviation for the guaranteed savings level compared to overestimating the expectation and underestimating the standard deviation as discussed in Observation 6.4, the expected profits obtained with these levels will deviate from the expected profit with the full information in a similar way.

If the distribution of the energy saving is known but its mean and the expectation are estimated with an error and the guaranteed saving level is determined with the 
estimates from the distribution, the expected profit of the user resulting from the balanced contract constructed with the estimates will differ from the exact level by $11 \%$ for these cases. So, when the distribution of the energy saving is not known and the expectation and the standard deviation of the energy saving are estimated with error, more than half of the deviation is due to not having the distributional information.

Table 5. Percentage difference of the user's expected profit resulting from the distribution-free simple contract with the estimated mean and the standard deviation compared to the user's expected profit from the optimal balanced contract with the full distributional information

\begin{tabular}{r|rrrrrrrrr|r}
$\epsilon_{\mu} \backslash \epsilon_{\sigma}$ & -0.20 & -0.15 & -0.10 & -0.05 & 0.00 & 0.05 & 0.10 & 0.15 & 0.20 & Avg. \\
\hline-0.20 & $105 \%$ & $108 \%$ & $111 \%$ & $114 \%$ & $117 \%$ & $120 \%$ & $123 \%$ & $127 \%$ & $130 \%$ & $117 \%$ \\
-0.15 & $77 \%$ & $79 \%$ & $82 \%$ & $85 \%$ & $88 \%$ & $90 \%$ & $93 \%$ & $96 \%$ & $100 \%$ & $88 \%$ \\
-0.10 & $50 \%$ & $52 \%$ & $55 \%$ & $57 \%$ & $60 \%$ & $63 \%$ & $65 \%$ & $68 \%$ & $71 \%$ & $60 \%$ \\
-0.05 & $25 \%$ & $28 \%$ & $30 \%$ & $32 \%$ & $35 \%$ & $37 \%$ & $39 \%$ & $42 \%$ & $44 \%$ & $35 \%$ \\
0.00 & $4 \%$ & $6 \%$ & $8 \%$ & $10 \%$ & $12 \%$ & $14 \%$ & $16 \%$ & $19 \%$ & $21 \%$ & $12 \%$ \\
0.05 & $-14 \%$ & $-12 \%$ & $-10 \%$ & $-8 \%$ & $-7 \%$ & $-5 \%$ & $-3 \%$ & $-1 \%$ & $1 \%$ & $-6 \%$ \\
0.10 & $-27 \%$ & $-26 \%$ & $-24 \%$ & $-23 \%$ & $-21 \%$ & $-19 \%$ & $-18 \%$ & $-16 \%$ & $-14 \%$ & $-21 \%$ \\
0.15 & $-36 \%$ & $-35 \%$ & $-34 \%$ & $-33 \%$ & $-31 \%$ & $-30 \%$ & $-28 \%$ & $-27 \%$ & $-25 \%$ & $-31 \%$ \\
0.20 & $-43 \%$ & $-42 \%$ & $-41 \%$ & $-40 \%$ & $-39 \%$ & $-37 \%$ & $-36 \%$ & $-35 \%$ & $-34 \%$ & $-39 \%$ \\
\hline Avg. & $16 \%$ & $18 \%$ & $20 \%$ & $22 \%$ & $24 \%$ & $26 \%$ & $28 \%$ & $30 \%$ & $33 \%$ & $24 \%$
\end{tabular}

Table 6 gives the percentage difference between the probability that the ESCO's total profit is lower than its upfront payment, $\operatorname{prob}\left(\Pi_{C} \leq 0\right)$, when it is determined by using the distribution-free simple contract with the estimated values of the mean and the standard deviation of the energy savings and its value when it is determined with the full distributional information. Table 3 shows that the distribution-free simple contract yields a lower probability of losing money for the ESCO. On average the probability of losing money for the ESCO resulting from the distribution-free contract is $8 \%$ lower than the full-information contract.

If the distribution of the energy saving is known but its mean and the standard deviation are estimated with error and the guaranteed savings level is determined with the estimates from the distribution, the probability of getting a total profit for the ESCO that is less than or equal to the upfront payment from the contract constructed with the estimates will differ from the exact level by $4 \%$ for these cases. Therefore, not having the distributional information adds another $4 \%$ deviation compared to the full information case.

These numerical experiments show that the distribution-free simple contract yields a lower guaranteed savings level compared to the level resulting from the balanced contract with full distributional information. However, setting the guaranteed savings level lower for the same fee that will be paid to the ESCO yields a higher expected profit to the energy user and a lower probability of getting a profit that is lower than the predetermined fee for the ESCO which shows that Observation 6.3 is still valid when the mean and the standard deviation are estimated with error and the distribution is not known. Since both of these outcomes are preferable for the energy user and the ESCO, our results support our last observation: 
Table 6. Percentage difference between the probability that the ESCO's Profit is non-positive $\left(\mathbf{p r o b}\left(\Pi_{C} \leq 0\right)\right.$ when it is determined by using the distribution-free simple contract with the estimated mean and the standard deviation and its value when it is determined with the full distributional information.

\begin{tabular}{r|rrrrrrrrr|r}
$\epsilon_{\mu} \backslash \epsilon_{\sigma}$ & -0.20 & -0.15 & -0.10 & -0.05 & 0.00 & 0.05 & 0.10 & 0.15 & 0.20 & Avg. \\
\hline-0.20 & $-55 \%$ & $-58 \%$ & $-60 \%$ & $-62 \%$ & $-64 \%$ & $-66 \%$ & $-69 \%$ & $-71 \%$ & $-73 \%$ & $-64 \%$ \\
-0.15 & $-44 \%$ & $-46 \%$ & $-48 \%$ & $-50 \%$ & $-54 \%$ & $-56 \%$ & $-57 \%$ & $-60 \%$ & $-62 \%$ & $-53 \%$ \\
-0.10 & $-32 \%$ & $-34 \%$ & $-36 \%$ & $-38 \%$ & $-40 \%$ & $-42 \%$ & $-45 \%$ & $-48 \%$ & $-50 \%$ & $-41 \%$ \\
-0.05 & $-19 \%$ & $-21 \%$ & $-23 \%$ & $-25 \%$ & $-27 \%$ & $-29 \%$ & $-31 \%$ & $-33 \%$ & $-35 \%$ & $-27 \%$ \\
0.00 & $-3 \%$ & $-5 \%$ & $-7 \%$ & $-9 \%$ & $-11 \%$ & $-12 \%$ & $-14 \%$ & $-16 \%$ & $-19 \%$ & $-11 \%$ \\
0.05 & $15 \%$ & $13 \%$ & $11 \%$ & $9 \%$ & $8 \%$ & $6 \%$ & $4 \%$ & $2 \%$ & $0 \%$ & $7 \%$ \\
0.10 & $32 \%$ & $31 \%$ & $29 \%$ & $28 \%$ & $26 \%$ & $24 \%$ & $23 \%$ & $21 \%$ & $19 \%$ & $26 \%$ \\
0.15 & $47 \%$ & $46 \%$ & $45 \%$ & $43 \%$ & $42 \%$ & $40 \%$ & $39 \%$ & $37 \%$ & $36 \%$ & $42 \%$ \\
0.20 & $57 \%$ & $56 \%$ & $55 \%$ & $54 \%$ & $53 \%$ & $51 \%$ & $50 \%$ & $49 \%$ & $48 \%$ & $53 \%$ \\
\hline Avg. & $0 \%$ & $-2 \%$ & $-4 \%$ & $-6 \%$ & $-7 \%$ & $-9 \%$ & $-11 \%$ & $-13 \%$ & $-15 \%$ & $-8 \%$
\end{tabular}

Observation 6.6. The distribution-free simple contract performs satisfactorily for the energy user and the ESCO even when the distribution of the energy savings is not known and its mean and the standard deviation are estimated with error.

\section{Conclusions}

In this study, we presented an analytical model to analyze the energy savings performance contracts and determine their parameters. We considered a general contract structure that includes guaranteed and target levels and also penalties and rewards that depend on realization of the energy savings with respect to the guaranteed and target levels.

As opposed to the previous studies that focus on determining some of the contract parameters when the others are set to specific values, this study focuses on the interrelationship among the contract parameters and shows how these parameters affect the risks of overestimating or underestimating the cost savings for the energy user and the ESCO.

By using the concept of a balanced contract, we derived the conditions that yield a feasible contract between the energy user and the ESCO. By using the statistical information available for the cost savings, we derived the equations that relate the contract parameters with each other when the cost saving distribution is uniform and normal. These conditions relate the parameters of the contract to each other and decrease the number of parameters that need to be considered when a contract is constructed.

In order to address the difficulty of estimating the energy savings that will be obtained from energy efficiency measures applied to a particular building or a manufacturing plant, we developed a distribution-free contract that yields the best-balanced contract for the worst savings distribution.

By analyzing the risk implications of a given contract on the ESCO and the energy user, we propose using a simple distribution-free contract that sets the guaranteed savings level at 0.35 standard deviation below the expected cost savings level and allocates the savings above this guaranteed level equally between the energy user and 


\section{the ESCO.}

Through a set of numerical experiments, we showed that this simple contract performs satisfactorily for the ESCO and for the energy user. This simple rule of thumb to set the guaranteed energy savings level is based on a rigorous analytical analysis to construct an energy savings performance contract. This result can be of interest to the practitioners especially if the statistical information about energy savings is limited.

Finally, our results show that the energy savings contracts with the right parameters can mitigate the risks related to realization of the anticipated energy savings. Therefore, we present the distribution-free balanced contract as a useful tool to set the right parameters of the energy savings contracts and mitigate the risks in an effective way.

This research can be extended in different ways. An economic model that incorporates moral hazard on part of the energy user and also the ESCO can be developed. This model can be used to determine why an energy user may not be able to invest in energy efficiency projects on its own. Furthermore, information asymmetry between the ESCO and the energy user on the cost of the project and the energy savings can be introduced. The fee negotiation based on the cost savings expected from the project can be incorporated directly to the model.

In this study, we incorporate the effect of the project length by defining the realized energy saving, the guaranteed and target energy saving levels as the quantities for the whole project duration. This approach assumes that the payments of the reward and penalties are done at the end of the project duration. In certain contracts, the timing of the payments can be different. Analysis of these variations can be performed by using the approach presented in this study. The analytical results discussed in this study can be combined with the computational approaches to determine the performance of a given multi-period contract by using available data. These extensions are left for future research.

\section{Appendix}

\section{Proof of Proposition 4.1}

In order to have a balanced contract, the expected gain from savings that exceed the target level should be greater than the value of giving a guarantee to the energy user for the amount of energy below the guaranteed level:

$$
E\left[(G-S)^{+}\right] \leq E\left[(S-T)^{+}\right]
$$

Equivalently,

$$
G \leq \mu-\left(E\left[(S-G)^{+}\right]-E\left[(S-T)^{+}\right)\right] .
$$

Since $T=G+\delta, \delta \geq 0$, the term in the parenthesis is non-negative. Therefore, $G$ must be less than or equal to $\mu$. Furthermore, if $G=T$, the term in the parenthesis is 0 , and $G \leq \mu$.

The term $E\left[(G-S)^{+}\right]$is non-decreasing with $G$ and the term $E\left[(S-T)^{+}\right]=E[(S-$ $\left.G-\delta)^{+}\right]$is non-increasing with G. Furthermore, at $G=0, E\left[(S-\delta)^{+}\right] \geq E\left[(0-S)^{+}\right]$. Therefore, there exists a unique $G^{*}$ where $E\left[\left(G^{*}-S\right)^{+}\right]=E\left[\left(S-G^{*}-\delta\right)^{+}\right]$and 
the contract is feasible for all values of $G \leq G^{*}$. For a given $G \leq G^{*}$, as $\delta$ increases $E\left[(S-G-\delta)^{+}\right]$decreases. Since $E\left[(S-G-\delta)^{+}\right] \geq 0$, there is an upper bound $\delta^{*}$ that makes $E\left[\left(S-G-\delta^{*}\right)^{+}\right]$arbitrarily close to 0 . As a result, there exists a threshold $\delta^{*}, 0 \leq \delta \leq \delta^{*}$ that results in a balanced contract $\left(G, G+\delta, \alpha_{l}, \beta \alpha_{l}\right)$ with $0 \leq \beta \leq 1$. Let $\delta(G)$ be the function that gives the upper bound for $\delta$ for a given value of $G . \delta(G)$ is non-increasing in $G$ with $\delta(\mu)=0$ and $\delta(0) \rightarrow \infty$.

\section{Proof of Proposition 4.2}

When $\operatorname{prob}\left(\Pi_{U}>\pi_{U}\right)=\operatorname{prob}\left(\Pi_{C}>\pi_{C}\right), \operatorname{prob}\left(\Pi_{U} \leq \pi_{U}\right)=\operatorname{prob}\left(\Pi_{C} \leq \pi_{C}\right)$. Then Equations (16) and (17) yield

$$
F\left(T+\frac{\pi_{U}}{\alpha_{p}}\right)=F\left(T+\frac{\pi_{C}}{1-\alpha_{p}}\right) .
$$

Accordingly,

$$
\alpha_{p}=\frac{\pi_{U}}{\pi_{U}+\pi_{C}}
$$

\section{Proof of Proposition 5.1}

Since both parties evaluate their benefits from the same realization of $S$, either $(G-$ $S)^{+} \geq 0$ and $(S-T)^{+}=0$ or $(G-S)^{+}=0$ and $(S-T)^{+} \geq 0$ for a given project. Therefore, we can write

$$
E\left[\left|(G-S)^{+}-\beta(S-T)^{+}\right|\right]=E\left[(G-S)^{+}\right]+\beta E\left[(S-T)^{+}\right] .
$$

Since the distribution of $S$ is not available, we can use the Cauchy-Schwarz inequality to relate the parameters of the contract:

$$
E\left[(S-T)^{+}\right] \leq \frac{1}{2}\left(\left(\sigma^{2}+(T-\mu)^{2}\right)^{\frac{1}{2}}-(T-\mu)\right) .
$$

Similarly,

$$
E\left[(G-S)^{+}\right] \leq G-\mu+\frac{1}{2}\left(\left(\sigma^{2}+(G-\mu)^{2}\right)^{\frac{1}{2}}-(G-\mu)\right) .
$$

Therefore,

$$
\begin{aligned}
E\left[\left|(G-S)^{+}-\beta(S-T)^{+}\right|\right] \leq G-\mu & +\frac{1}{2}\left(\left(\sigma^{2}+(G-\mu)^{2}\right)^{\frac{1}{2}}-(G-\mu)\right) \\
& +\frac{\beta}{2}\left(\left(\sigma^{2}+(T-\mu)^{2}\right)^{\frac{1}{2}}-(T-\mu)\right) .
\end{aligned}
$$

If both parties want to make it sure that the resulting profits are as close as possible to the balanced contract under the worst distribution of the cost saving, they can 
determine the $G$ and $T(T \geq G)$ to minimize the upper bound of the expected value of the absolute difference between $E\left[(G-S)^{+}\right]$and $\beta E\left[(S-T)^{+}\right]$.

Note that minimizing the expected cost for the worst distribution of demand is used as the main criterion to determine the distribution-free optimal order quantity in the newsvendor problem (Gallego and Moon 1993).

Accordingly, the following optimization problem is solved to determine $G$ and $T$ for a given value of $\beta$ :

$$
\begin{aligned}
\min _{G, T} G-\mu & +\frac{1}{2}\left(\left(\sigma^{2}+(G-\mu)^{2}\right)^{\frac{1}{2}}-(G-\mu)\right) \\
& +\frac{\beta}{2}\left(\left(\sigma^{2}+(T-\mu)^{2}\right)^{\frac{1}{2}}-(T-\mu)\right) .
\end{aligned}
$$

The solution of the optimization problem given in Equation (37) subject to the constraint $T \geq G \geq 0$ gives the guaranteed cost saving level for a given profit-sharing ratio as

$$
G^{*}=T^{*}=\mu-\frac{1-\beta}{2 \sqrt{\beta}} \sigma
$$

\section{Proof of Proposition 5.2}

When $\operatorname{prob}\left(\Pi_{U}>\pi_{U}\right)=\operatorname{prob}\left(\Pi_{C}>\pi_{C}\right)$ and $\pi_{U}=\pi_{C}$, Proposition 2 yields $\alpha_{p}=$ $\frac{\pi_{U}}{\pi_{U}+\pi_{C}}=\frac{1}{2}$. Since $\alpha_{l}=1, \beta=\alpha_{p}=\frac{1}{2}$. Then, according to Proposition 3, Equation (38) gives $\frac{1-\beta}{2 \sqrt{\beta}}=\frac{\sqrt{2}}{4}$ and

$$
G=\mu-\frac{\sqrt{2}}{4} \sigma
$$

\section{References}

Aflaki, S., P. R. Kleindorfer, M. Polvorinos, and V. Sáenz (2013). Finding and implementing energy efficiency projects in industrial facilities. Production and Operations Management 22(3), 503-517.

Bertoldi, P. and B. Boza-Kiss (2017). Analysis of barriers and drivers for the development of the ESCO markets in Europe. Energy Policy 107, 345-355.

Blass, V., C. J. Corbett, M. A. Delmas, and S. Muthulingam (2014). Top management and the adoption of energy efficiency practices: Evidence from small and medium-sized manufacturing firms in the US. Energy 65, 560-571.

Brueske, S., R. Sabouni, C. Zach, and H. Andrest (2012). U.S. manufacturing energy use and greenhouse gas emissions analysis. Technical Report ORNL/TM-2012/504, Oak Ridge National Laboratory, Oak Ridge, TN, USA.

Carbonara, N. and R. Pellegrino (2018). Public-private partnerships for energy efficiency projects: A win-win model to choose the energy performance contracting structure. Journal of Cleaner Production 170, 1064-1075. 
Coppens, R. R. (2013). Energy performance contracting: a risk management decision model for the promotion of energy efficiency by using Monte Carlo simulation. Master's thesis, Technische Universiteit Eindhoven.

Corbett, C. J. and G. A. DeCroix (2001). Shared-savings contracts for indirect materials in supply chains: Channel profits and environmental impacts. Management Science 47(7), 881-893.

Corbett, C. J., G. A. DeCroix, and A. Y. Ha (2005). Optimal shared-savings contracts in supply chains: Linear contracts and double moral hazard. European Journal of Operational Research 163(3), 653-667.

Deng, Q., X. Jiang, Q. Cui, and L. Zhang (2015). Strategic design of cost savings guarantee in energy performance contracting under uncertainty. Applied Energy 139, 68-80.

Deng, Q., L. Zhang, Q. Cui, and X. Jiang (2014). A simulation-based decision model for designing contract period in building energy performance contracting. Building and Environment 71, 71-80.

Edgar, T. F. and E. N. Pistikopoulos (2018). Smart manufacturing and energy systems. Computers \& Chemical Engineering 114, 130-144.

EIA (2017). International Energy Outlook. U.S. Energy Information Administration. https://www.eia.gov/outlooks/ieo/pdf/0484(2017).pdf.

Gallego, G. and I. Moon (1993). The distribution free newsboy problem: review and extensions. Journal of the Operational Research Society, 825-834.

Glumac, B., M. A. Oosterbaan, W. F. Schaefer, and K. Sulla (2015). Implementing energy saving measures: A decision support tool for corporate real estate management. Journal of Corporate Real Estate 17(2), 134-156.

Goldman, C. A., N. C. Hopper, and J. G. Osborn (2005). Review of U.S. ESCO industry market trends: an empirical analysis of project data. Energy Policy 33(3), 387-405.

IEA (2018). 2018 Global Status Report. International Energy Agency. https://webstore.iea.org/2018-global-status-report.

IEA (2019). Material Efficiency in Clean Energy transitions. International Energy Agency. https://www.iea.org/publications/reports/MaterialEfficiencyinCleanEnergyTransitions/.

Lee, P., P. Lam, and W. Lee (2015). Risks in energy performance contracting (EPC) projects. Energy and Buildings 92, 116-127.

Lee, P., P. Lam, F. W. Yik, and E. H. Chan (2013). Probabilistic risk assessment of the energy saving shortfall in energy performance contracting projects-a case study. Energy and Buildings 66, 353-363.

Lee, S., S. Tae, and S. Shin (2015). Profit distribution in guaranteed savings contracts: Determination based on the collar option model. Sustainability 7(12), 16273-16289.

Muthulingam, S., C. J. Corbett, S. Benartzi, and B. Oppenheim (2013). Energy efficiency in small and medium- sized manufacturing firms: Order effects and the adoption of process improvement recommendations. Manufacturing and Service Operations Management 15(4), 596-615.

Qin, Q., F. Liang, L. Li, and Y.-M. Wei (2017). Selection of energy performance contracting business models: A behavioral decision-making approach. Renewable and Sustainable Energy Reviews 72, 422-433.

Rezessy, S. and P. Bertoldi (2010). Financing energy efficiency: forging the link between financing and project implementation. Technical report, European Commission.

Selviaridis, K. and F. Wynstra (2015). Performance-based contracting: a literature review and future research directions. International Journal of Production Research 53(12), 3505-3540.

Shang, T., K. Zhang, P. Liu, and Z. Chen (2017). A review of energy performance contracting business models: Status and recommendation. Sustainable Cities and Society 34, 203-210.

Shang, T., K. Zhang, P. Liu, Z. Chen, X. Li, and X. Wu (2015). What to allocate and how to allocate? benefit allocation in shared savings energy performance contracting projects. Energy 91, 60-71.

Shantia, A., S. Aflaki, and A. Masini (2018). Energy efficiency contracting in supply chains under asymmetric bargaining power. HEC Paris Research Paper No. MOSI-2015-1106. 
Stuart, E., J. P. Carvallo, P. H. Larsen, C. A. Goldman, and D. Gilligan (2018). Understanding recent market trends of the US ESCO industry. Energy Efficiency 11(6), 1303-1324.

Tan, B. and Y. Yavuz (2015). Modelling and analysis of a business model to offer energy-saving technologies as a service. International Journal of Production Research 53(23), 7118-7135.

Tan, B., Y. Yavuz, E. N. Otay, and E. Camlıbel (2016). Optimal selection of energy efficiency measures for energy sustainability of existing buildings. Computers $\&$ Operations Research 66, 258-271.

Töppel, J. and T. Tränkler (2019). Modeling energy efficiency insurances and energy performance contracts for a quantitative comparison of risk mitigation potential. Energy Economics 80, 842-859.

Trianni, A., E. Cagno, and S. Farné (2016). Barriers, drivers and decision-making process for industrial energy efficiency: A broad study among manufacturing small and medium-sized enterprises. Applied Energy 162, 1537-1551.

Vine, E. (2005). An international survey of the energy service company (ESCO) industry. Energy Policy 33(5), 691-704.

Yi, Y. and J. Li (2018). Cost-sharing contracts for energy saving and emissions reduction of a supply chain under the conditions of government subsidies and a carbon tax. Sustainability 10(3), 895.

Yik, F. W.-H. and W.-L. Lee (2004). Partnership in building energy performance contracting. Building Research 8 Information 32(3), 235-243.

Zhou, W. and W. Huang (2016). Contract designs for energy-saving product development in a monopoly. European Journal of Operational Research 250(3), 902-913. 